Article

\title{
Polyphenol Extraction by Different Techniques for Valorisation of Non-Compliant Portuguese Sweet Cherries towards a Novel Antioxidant Extract
}

\author{
Ana A. Vilas-Boas ${ }^{1}{ }^{(\mathbb{C}}$, Débora A. Campos ${ }^{1}{ }^{(0)}$, Catarina Nunes ${ }^{2}$, Sónia Ribeiro ${ }^{2}$, João Nunes ${ }^{2}$, \\ Ana Oliveira ${ }^{1}(\mathbb{B})$ and Manuela Pintado ${ }^{1, *}$ \\ 1 CBQF-Centro de Biotecnologia e Química Fina-Laboratório Associado, Escola Superior de Biotecnologia, \\ Universidade Católica Portuguesa, 4200-374 Porto, Portugal; avboas@porto.ucp.pt (A.A.V.-B.); \\ dcampos@porto.ucp.pt (D.A.C.); alsoliveira84@gmail.com (A.O.) \\ 2 Association BLC3-Technology and Innovation Campus, Centre Bio R\&D Unit, Senhora da Conceição, \\ 3045-155 Oliveira do Hospital, Portugal; catarina.nunes@blc3.pt (C.N.); sonia.ribeiro@blc3.pt (S.R.); \\ joao.nunes@blc3.pt (J.N.) \\ * Correspondence: mpintado@porto.ucp.pt
}

Received: 21 May 2020; Accepted: 25 June 2020; Published: 10 July 2020

\begin{abstract}
Currently, there is special interest in the recovery of polyphenols from non-compliant fruits that have no market value; efforts to find value-added solutions for these food areas are a key option for a sustainable bio-economy. Saco cherries are a traditional Portuguese cherry variety, and although they are a nutritionally important food, rich in powerful dietary polyphenols, significant amounts of these cherries are not sold due to their small size. In this context, this work aimed to select the best method to produce novel antioxidant polyphenol-rich extracts from low calibre and non-compliant Saco cherries. Based on the results, microwaves-assisted extraction (MAE) allowed us to obtain a polyphenol-rich extract with a high antioxidant capacity $(50.46 \pm 1.58 \mathrm{mg}$ Trolox equivalent (TE)/g dry extract (DE) by oxygen radical absorbance capacity (ORAC), $10.88 \pm 0.38 \mathrm{mg}$ ascorbic acid equivalent (AA)/g DE by 2-azinobis-3-ethylbenzothiazoline-6-sulphonic acid (ABTS), and $9.58 \pm 0.42 \mathrm{mg}$ TE/g DE by 2,2-diphenyl-1-picrylhydrazyl (DPPH)) and a high content of polyphenols, namely, hydroxycinnamic acids (neochlorogenic and $p$-coumaric acids) and anthocyanins (cyanidin-3-rutinoside and cyanidin-3-glucoside), compared with those of conventional extractions with low and high temperature and ultrasound-assisted extraction. The antioxidant extract produced from MAE could be a new alternative for the valorisation of non-compliant cherries since these extracts proved to be a functional ingredient due to the high content of antioxidants, which are linked to the prevention of diseases.
\end{abstract}

Keywords: Saco cherry; non-compliant; polyphenols; antioxidant activity; extraction method

\section{Introduction}

Sweet cherries (Prunus avium L.) are among the most attractive fruit to consumers, due to their taste, sweetness, firmness, colour [1], and a high content of health-promoting compounds [2]. Beira Interior is a Portuguese region that has the largest sweet cherry production in Portugal with the protected geographical indication (PGI) registered Cova da Beira cherry. Annually, the production of Cova da Beira cherries reaches around $17,000 \mathrm{t}$, with the Saco sweet cherry variety being the oldest and the most produced [3,4]. In the context of a bio-economy, the Saco cherry variety is the most important in the Cova da Beira region. Climate change, phytosanitary uncertainties, and the dependence of consumers on fresh fruit have led to the need for research and implementation of new high-value pathways for low-calibre and non-compliant fruit, without compromising sustainability, by increasing the circular 
bio-economy in this sector (decreasing the food losses). Several studies showed that Saco cherries have interesting characteristics from nutritional and bioactive points of view, mainly associated to their composition of different dietary phenolic compounds such as phenolic acids, flavonoids, anthocyanins, flavan-3-ols, and flavanols; however, the anthocyanins are the most interesting polyphenols present in sweet cherries [4,5]. Furthermore, these phenolic compounds are correlated with great antioxidant activity, which is associated with improved health benefits, playing an important role in preventing several chronic diseases [5]. Saco cherry production generates a high amount of non-compliant fruit, i.e., fruit that does not meet the standards required to be marketed due to its low calibre/size. Furthermore, sweet cherries are highly perishable fruits with a short shelf-life and postharvest-life, and are expensive to acquire and produce [6]. However, the traditional varieties are a source of distinctive genetic characters derived from many years of adaptation to the original territory [7] and reflect the high Portuguese biodiversity. Due to the aforementioned constraints due to non-compliant fruit, Saco cherries do not have high value in the market and, for that reason, are considered a food loss, which if not reused, will lead to negative environmental and economic impacts [8]. This represents an opportunity in the agricultural sector in terms of biodiversity preservation, environmental sustainability, and valorisation of the final products [7].

In the past few years, there has been an increased interest in the recovery of bioactive compounds (BCs) from this kind of fruit to comply with the circular economy concept. Similarly, social awareness linked to natural food markets has been rising and focusing on food losses valorisation and a move towards natural ingredients free of harmful chemicals to preserve personal health and safety [9]. However, when producing extracts, there is the need to keep the integrity of the active molecules and assure, at the same time, consumer safety and environmental sustainability.

The development of new strategies to meet new market demands when producing natural antioxidant extracts is of extreme importance because the commonly used conventional extraction (CE) methods, such as maceration, consume high amounts of solvents, time, and energy, and are a hazard to the environment [10]. Green chemistry-based extraction methods could be the option applied to meet the circular economy goals, reducing the negative environmental impact of the conventional extraction methods. Hence, the optimization of these processes via the development of an appropriate non-toxic extraction solvent system or via the use of emergent extraction techniques has been studied [11]. Theoretically, the optimal extraction method should be simple, safe, reproducible, inexpensive, and suitable for industrial application [12]. As CE usually takes more time and requires large volumes of solvents, nonconventional extraction methods such as microwave-assisted extraction (MAE) and ultrasound-assisted extraction (UAE), among others, are being used for the recovery of polyphenols and other compounds from fruits like cherries [13,14]. Currently, great attention has been given to green extraction technologies, since they can reduce or eliminate the use of hazardous substances and limit the cost of solvent waste disposal [15]. MAE allows for high-temperature extraction, but with reduced extraction times, thereby consuming less energy. The amount of solvent used is smaller when compared to that used by conventional extraction methods. On the other hand, UAE has low extraction time with high recovery yields, but in contrast to MAE, this extraction applies lower temperatures. UAE has been widely applied to the production of bioactive extracts from plants and fruits since it is especially good at breaking the cell walls, leading to the release and recovery of high-quality BCs $[13,16]$. So far, three research works studied the production of polyphenolic-rich extracts from Saco cherries using conventional hydro-alcoholic extraction without high temperature, followed by separation and adsorption processes [8,17], and through two-steps of supercritical $\mathrm{CO}_{2}$ extraction [18]. To the best of our knowledge, this is the first time that MAE and UAE were applied to non-compliant Saco cherries to produce novel antioxidant extracts.

In this work, two green extraction techniques (MAE and UAE) were compared with CE (with low and high temperatures) to select the best technique to produce a novel antioxidant polyphenol-rich extract from non-compliant Portuguese Saco sweet cherries for further applications as a functional ingredient with antioxidant activity in food products. 


\section{Materials and Methods}

\subsection{Chemicals}

The 2-azinobis-3-ethylbenzothiazoline-6-sulphonic acid (ABTS), 2,2'-azo-bis-(2methylpropionamidine)-dihydrochloride (AAPH), 2,2-diphenyl-1-picrylhydrazyl (DPPH), 3-caffeoylquinic acid, 4-caffeoylquinic acid, 4,5-Di-O-caffeoylqinic acid, 5-caffeoylquinic acid, ascorbic acid, caffeic acid, fluorescein, gallic acid, $p$-coumaric acid, potassium chloride $(\mathrm{KCl})$, sodium acetate $\left(\mathrm{CH}_{3} \mathrm{CONa}\right)$, sodium carbonate $\left(\mathrm{Na}_{2} \mathrm{CO}_{3}\right)$, trifluoroacetic acid (TFA), and trolox were purchased from Sigma-Aldrich (Sintra, Portugal). (-)-Epicatechin-3-gallate, cyanidin-3-glucoside, cyanidin-3-rutinoside, kaempferol-3-glucoside, pelargonidin-3-rutinoside, peonidin-3-rutinoside, quercetin, and quercetin-3-rutinoside were purchased from Extrasynthése (Genay Cedex, France). Acetonitrile and methanol were purchased from Fischer Scientific (Oeiras, Portugal). Folin-Ciocalteu's reagent, hydrochloric acid $37 \%(v / v)(\mathrm{HCl})$, and potassium persulfate were purchased from Merck (Algés, Portugal).

\subsection{Fruit Material and Preparation of Extracts}

\subsubsection{Fruit Material}

Low calibre and/or non-compliant sweet cherries (Prunus avium L.) from the Saco variety, grown in Fundão-Cova da Beira, Portugal $\left(40^{\circ} 08^{\prime} 24.90^{\prime \prime}\right.$ N- $\left.7^{\circ} 30^{\prime} 4.86^{\prime \prime} \mathrm{W}\right)$, were provided by “CerfundãoEmbalamento e Comercialização de Cereja Cova da Beira, Lda." company from Fundão, in May 2018 at the commercial maturity stage. The cherries were stored in a cold room at $6{ }^{\circ} \mathrm{C}$ during the analysis time ( 2 weeks). The stems and the pits were removed by hand and washed in cold water, and then dipped in $100 \mu \mathrm{g} / \mathrm{L}$ of sodium hypochlorite solution for $1 \mathrm{~min}$. After that, the cherries were crushed to obtain a homogenous pulp, before the extraction procedures.

\subsubsection{Preparation of Saco Cherry Extracts}

Classical extraction with low temperature (CE) and with high temperature (CET): The extraction with low temperature was made at room temperature $\left(23^{\circ} \mathrm{C}\right)$ over $1 \mathrm{~h}$ by stirring $10 \mathrm{~g}$ of crushed cherries with $30 \mathrm{~mL}$ ethanol/water $(50: 50, v / v)$ acidified with $0.1 \%$ of $\mathrm{HCl}$, previously homogenized using Ultra Turrax (Ultra Turrax T-25, IKA, Germany) at $9500 \mathrm{rpm}$ for $60 \mathrm{~s}$. Extraction with high temperature was performed in the same way, but after homogenization, extraction continued with stirring at $65 \pm 1{ }^{\circ} \mathrm{C}$ over $30 \mathrm{~min}$.

Microwaves-assisted extraction (MAE): $10 \mathrm{~g}$ of crushed cherries were homogenized with $30 \mathrm{~mL}$ ethanol/water (50:50, $v / v)$ acidified with $0.1 \%$ de $\mathrm{HCl}$ using an Ultra Turrax at $9500 \mathrm{rpm}$ for $60 \mathrm{~s}$. The extraction was made using a single-mode focused microwave reactor (Milestone, Start S Microwave Labstation for Synthesis, Italy, with a rotor SK-12) operating at $2450 \mathrm{MHz}$ with adjustable microwave power, without exceeding $65^{\circ} \mathrm{C}$. General extraction parameters were: $300 \mathrm{~W}$ during $15 \mathrm{~min}$, divided into 3 identical cycles of $5 \mathrm{~min}$, with an interval of $5 \mathrm{~min}$ between cycles.

Ultrasound-assisted extraction (UAE): $10 \mathrm{~g}$ of crushed cherries were homogenized by Ultra Turrax at $9500 \mathrm{rpm}$ for $60 \mathrm{~s}$ with $30 \mathrm{~mL}$ ethanol/water $(50: 50, v / v)$ acidified with $0.1 \%$ of $\mathrm{HCl}$. The sonication proceeded for $30 \mathrm{~min}$ in an ultrasonic bath (Laborette 17, Fritsch, Germany) with $120 \mathrm{~W}$ application power and a frequency range of $50-60 \mathrm{~Hz}$ with temperature control $\left(30^{\circ} \mathrm{C}\right)$.

Afterwards, all the extracts obtained above were cooled at room temperature and were centrifuged (K241, Centurion Scientific Ltd., Chichester, UK) at $2600 \mathrm{G}$ for $20 \mathrm{~min}$. The supernatant was retained, the ethanol fraction evaporated at $40^{\circ} \mathrm{C}, 175$ mbar pressure by rotary evaporator, and the remaining aqueous extract was reduced to powder by freeze-drying (LyoQuest-85, Telstar, Portugal). All extraction 
techniques were done in three independent extractions. The extraction yield was calculated based on the amount of fresh Saco cherry used to make the extracts (Equation (1)).

$$
\text { Extractive Yield }(\%)=\frac{\text { Dried extract }(\mathrm{g})}{\text { Fresh weight of fruit }(\mathrm{g})} \times 100
$$

\subsection{Total Phenolic Content}

Total phenolic content (TPC) of the cherry extracts was determined by Folin-Ciocalteu method [19] with some modifications. Briefly, $80 \mu \mathrm{L}$ of Folin-Ciocalteu reagent $10 \%(v / v)$ was added to $20 \mu \mathrm{L}$ of extract (previously dissolved in distilled water), followed by $100 \mu \mathrm{L}$ of sodium carbonate $(7.5 \%(\mathrm{~m} / \mathrm{v}))$ and allowed to react in the dark at room temperature $\left(23{ }^{\circ} \mathrm{C}\right)$ for $1 \mathrm{~h}$. After that, absorbance was measured at $750 \mathrm{~nm}$ (Multiskan GO Microplate Spectrophotometer, Thermo Fisher Scientific Inc., Waltham, MA, USA) in a 96-well microplate (Nunc ${ }^{\mathrm{TM}}$, Thermo Fisher Scientific Inc., Waltham, MA, USA). Gallic acid was used as a standard for the calibration curve $(0.010-0.125 \mathrm{mg} / \mathrm{mL}$, $\left.y=5.991 x+0.126, R^{2}=0.999\right)$ and the results were expressed as milligrams equivalent of gallic acid per gram of dry extract (mg GAE/g DE). Three independent analyses were performed in each of the triplicate extracts obtained for each different methodology.

\subsection{Total Anthocyanins}

Total anthocyanins content (TAC) of cherry extracts was determined by the $\mathrm{pH}$-differential spectroscopic method described by Lee et al. [20]. Briefly, $250 \mu \mathrm{L}$ of each extract (previously dissolved and after diluted in distilled water) was mixed with $750 \mu \mathrm{L}$ of two different buffers: Potassium chloride $(\mathrm{KCl})$ at $\mathrm{pH} 1.0$ and sodium acetate $\left(\mathrm{CH}_{3} \mathrm{CONa}\right)$ at $\mathrm{pH} 4.5$. The absorbance was measured at 515 and $700 \mathrm{~nm}$ (UV mini 1240, Shimadzu, Tokyo, Japan) after incubation for $20 \mathrm{~min}$ at room temperature $\left(23^{\circ} \mathrm{C}\right)$. Absorbance (A) was calculated as follows in Equation (2), and then the TAC, in mg/L, was estimated by Equation (3). Finally, the results were converted and expressed as milligrams of cyanidin-3-glucoside equivalent per g of dry extract (mg Cy-3-glu/g DE).

$$
\begin{gathered}
\mathrm{A}=\left(\text { Abs }_{515 \mathrm{~nm}}-\mathrm{Abs}_{700 \mathrm{~nm}}\right) \mathrm{pH1.0-}\left(\text { Abs }_{515 \mathrm{~nm}}-\mathrm{Abs}_{700 \mathrm{~nm}}\right) \mathrm{pH} 4.5 \\
\mathrm{C}(\mathrm{mg} / \mathrm{L})=(\mathrm{A} \times \mathrm{MW} \times \mathrm{DF} \times 1000) \div \varepsilon \times \mathrm{L}
\end{gathered}
$$

where molecular weight (MW) and molar extinction coefficient $(\varepsilon)$ of cyanidin-3-glucoside is $449.2 \mathrm{~g} / \mathrm{mol}$ and $\mathrm{L} / \mathrm{mol}^{*} \mathrm{~cm}$, respectively; cuvette optical path length (L) is $1 \mathrm{~cm}$, and final dilution factor (DF) is 80. Three independent analyses were performed in each of the triplicate extracts obtained for each different methodology.

\subsection{Phenolic Compounds Identification by LC-ESI-QqTOF-HRMS}

Antioxidant extracts were dissolved in ultrapure water at $20 \mathrm{mg} / \mathrm{mL}$ for further analysis by LC-ESI-UHR-QqTOF-MS according to Monforte et al. [21] with some modifications. The separation was performed in a UHPLC UltiMate 3000 Dionex (Thermo Scientific), coupled to an ultrahigh-resolution, Qq-time-of-flight (UHR-QqTOF) mass spectrometer with 50,000 full-sensitivity resolution (FSR) (Impact II, Bruker Daltonics, Bremen, Germany). Separation of metabolites was performed using an Acclaim RSLC 120 C18 column $(100 \mathrm{~mm} \times 2.1 \mathrm{~mm}, 2.2 \mu \mathrm{m})$ (Dionex). Mobile phases were $0.1 \%$ aqueous formic acid (solvent A) and acetonitrile with $0.1 \%$ formic acid (solvent B). Separation was carried out over $24.5 \mathrm{~min}$ under the following gradient conditions: $0 \mathrm{~min}, 0 \% \mathrm{~B} ; 10 \mathrm{~min}, 21.0 \% \mathrm{~B} ; 14 \mathrm{~min}$, $27 \% \mathrm{~B} ; 18.30 \mathrm{~min}, 58 \%$; $20.0 \mathrm{~min}, 100 \% ; 24.0 \mathrm{~min}, 100 \% ; 24.10 \mathrm{~min}, 0 \% ; 26.0 \mathrm{~min}, 0 \%$ at a flow rate of $0.25 \mathrm{~mL} / \mathrm{min}$. The injection volume was $5 \mu \mathrm{L}$. Parameters for MS analysis were set using negative ionization mode with spectra acquired over a range from $\mathrm{m} / \mathrm{z} 20$ to 1000 . The parameters were as follows: Capillary voltage, $3.0 \mathrm{kV}$; drying gas temperature, $200{ }^{\circ} \mathrm{C}$; drying gas flow, $8.0 \mathrm{~L} / \mathrm{min}$; nebulizing gas pressure, 2 bar; collision RF, $300 \mathrm{Vpp}$; transfer time, $120 \mu \mathrm{s}$; and prepulse storage, $4 \mu \mathrm{s}$. 
Post-acquisition internal mass calibration used sodium formate clusters, with the sodium formate delivered by a syringe pump at the start of each chromatographic analysis. High-resolution mass spectrometry was used to identify the compounds. The elemental composition for the compound was confirmed according to accurate mass and isotope rate calculations designated mSigma (Bruker Daltonics). The accurate mass measurement was within $5 \mathrm{mDa}$ of the assigned elemental composition, and mSigma values of $<20$ provided confirmation. Compounds were identified based on its accurate mass $[\mathrm{M}-\mathrm{H}]^{-}$. Three independent analyses were performed in each of the triplicate extracts obtained for each different methodology.

\subsection{Phenolic Compounds Quantification by HPLC}

The quantitative profile of phenolic compounds in cherry extracts (previously dissolved in ultrapure water) was performed using a Waters Alliance e2695 separation module system interfaced with a photodiode array UV/Vis detector 2998 (PDA 190-600 nm) (Waters, Mildford, MA, USA). The separation of the compounds was carried out in a reverse-phase C18 column (COSMOSIL 5C1 8-AR-II Packed Column-4.6 mm I.D. $\times 250 \mathrm{~mm}$; Dartford, UK). The mobile phases and the gradient program used were prepared according to Oliveira et al. [22] with some modifications. The mobile phase was composed of solvent A: Water/acetonitrile/TFA (94.9/5/0.1\%) and solvent B: Acetonitrile/TFA (99.9/0.1\%) with the elution gradient: $0-1 \min 0 \% \mathrm{~B} ; 1-30 \min 21 \% \mathrm{~B} ; 30-42 \min 27 \% \mathrm{~B} ; 45-55 \min 58 \%$ B; $55-60 \mathrm{~min} 0 \% \mathrm{~B}$, and kept another $1 \mathrm{~min}$ at $0 \% \mathrm{~B}$. Flow rate was $1 \mathrm{~mL} / \mathrm{min}$, the oven temperature was set as $25^{\circ} \mathrm{C}$, and the injection volume was $20 \mu \mathrm{L}$. Detection was performed at $280 \mathrm{~nm}, 320 \mathrm{~nm}, 360 \mathrm{~nm}$, and 520 $\mathrm{nm}$, while data acquisition and analysis were accomplished using Software Empower 3. Identification of compounds was done by comparing the retention times and spectra with pure standards (3-, 4-, 5-, 4,5caffeoylquinic acids, caffeic acid, epicatechin-3-gallate, kaempferol-3-glucoside, cyanidin-3-glucoside, cyanidin-3-rutinoside, peonidin-3-rutinoside, pelargonidin-3-rutinoside, protocatechuic acid and $p$-coumaric acid, quercetin-3-rutinoside, and quercetin). Herein, $p$-coumaroylquinic acid was calculated as equivalents of $p$-coumaric acid. The quantification was performed by the calibration curves and the results were expressed as milligrams per gram of dry extract (mg/g DE). In Table 1 are present the validation criteria of the phenolic compounds for the equipment. Three independent analyses were performed in each of the triplicate extracts obtained for each different methodology. 
Table 1. Calibration curves, Limit of Detection (LoD), and Limit ofQuantification (LoQ) of pure standards use for quantification of polyphenols by HPLC, and results for the repeatability and recovery.

\begin{tabular}{|c|c|c|c|c|c|c|c|}
\hline \multirow{2}{*}{ Phenolic Compounds } & \multicolumn{7}{|c|}{ Validation Criteria } \\
\hline & Slope & Intercept & $\mathbf{R}^{2}$ & $\operatorname{LoD}(\mathrm{mg} / \mathrm{mL})$ & LoQ (mg/mL) & Repeatability (\% RSD) & \% Recovery \\
\hline \multicolumn{8}{|c|}{ Hydroxycinnamic acids } \\
\hline 3-Caffeoylquinic acid & $54,993,453$ & 195,577 & 0.998 & 0.02 & 0.06 & 0.382 & 92.684 \\
\hline 5-Caffeoylquinic acid & $57,646,292$ & 302,485 & 0.999 & 0.01 & 0.04 & 0.838 & 101.219 \\
\hline 4-Caffeoylquinic acid & $55,692,713$ & 116,655 & 0.999 & 0.01 & 0.05 & 0.430 & 98.995 \\
\hline 4,5-dicaffeoylquinic acid & $31,929,586$ & 91,582 & 0.999 & 0.01 & 0.03 & 0.566 & 97.548 \\
\hline Caffeic acid & $109,109,858$ & 485,096 & 0.998 & 0.01 & 0.06 & 0.139 & 99.510 \\
\hline$p$-coumaric acid & $110,590,209$ & 213,534 & 0.999 & 0.01 & 0.04 & 0.331 & 99.801 \\
\hline \multicolumn{8}{|c|}{ Flavan-3-ols } \\
\hline (-)-Epicatechin-3-gallate & $35,497,526$ & 38,356 & 0.999 & 0.01 & 0.02 & 0.417 & 98.887 \\
\hline \multicolumn{8}{|c|}{ Flavonols } \\
\hline Quercetin-3-rutinoside & $31,584,226$ & 132,541 & 0.998 & 0.02 & 0.05 & 0.162 & 98.591 \\
\hline Kaempferol-3-glucoside & $40,663,899$ & 30,580 & 0.999 & 0.01 & 0.04 & 1.087 & 95.975 \\
\hline Quercetin & $86,817,569$ & 360,940 & 0.998 & 0.02 & 0.06 & 0.210 & 96.823 \\
\hline \multicolumn{8}{|c|}{ Anthocyanins } \\
\hline Cyanidin-3-rutinoside & $53,088,951$ & 91,623 & 0.999 & 0.01 & 0.02 & 0.855 & 100.749 \\
\hline Cyanidin-3-glucoside & $13,535,732$ & $-39,433$ & 0.999 & 0.01 & 0.03 & 0.346 & 97.235 \\
\hline Peonidin-3-rutinoside & $51,163,043$ & 256,007 & 0.998 & 0.02 & 0.06 & 0.411 & 98.820 \\
\hline Pelargonidin-3-rutinoside & $46,960,315$ & $-54,554$ & 0.999 & 0.01 & 0.04 & 0.471 & 100.005 \\
\hline
\end{tabular}




\subsection{Antioxidant Activity}

The antioxidant activity of cherry extracts was determined using three different methods:

\subsubsection{The ABTS Method}

Was performed according to Gião et al. [23]. Briefly, the free radical $\mathrm{ABTS}^{\circ}$ was generated through a chemical oxidation reaction with potassium persulfate. After that, the concentration of $\mathrm{ABTS}^{\circ}$ was adjusted with water to an initial absorbance of $0.700 \pm 0.020$ at $734 \mathrm{~nm}$ (Multiskan GO Microplate Spectrophotometer, Thermo Scientific, Thermo Fisher Scientific Inc., Waltham, MA, USA). The sample $(15 \mu \mathrm{L})$, previously dissolved in distilled water, was allowed to react in the dark at room temperature $\left(23^{\circ} \mathrm{C}\right)$ with $200 \mu \mathrm{L}$ of diluted $\mathrm{ABTS}^{\circ}$ solution, and the absorbance was read exactly 6 min after initial mixing in a 96-well microplate (Nunc ${ }^{\mathrm{TM}}$, Thermo Fisher Scientific Inc., Waltham, MA, USA). A blank was taken with distilled water (A0). The inhibition percentage (I) of the sample was calculated using Equation (4) and compared with the ascorbic acid standard calibration curve $(0.0088-0.088 \mathrm{mg} / \mathrm{mL}$, $\left.y=1103.3 x-6.206, R^{2}=0.999\right)$. The results were expressed as milligrams of ascorbic acid equivalent per gram of dry extract (mg AAE/g DE). Three independent analyses were performed in each of the triplicate extracts obtained for each different methodology.

\subsubsection{The DPPH Assay}

Was carried out according to the procedure described by Alexandre, Silva, Santos, Silvestre, Duarte, Saraiva, and Pintado [19], with some modifications. Briefly, a stock solution $(600 \mu \mathrm{M})$ was prepared by dissolving $24 \mathrm{mg}$ of DPPH in $100 \mathrm{~mL}$ of methanol, and stored at $-20^{\circ} \mathrm{C}$ in the darkness. Work solution $(60 \mu \mathrm{M})$ was prepared to mix $10 \mathrm{~mL}$ of stock solution with $90 \mathrm{~mL}$ of methanol so absorbance reached $0.700 \pm 0.02$ at $515 \mathrm{~nm}$ (Multiskan GO Microplate Spectrophotometer, Thermo Scientific, Thermo Fisher Scientific Inc., Waltham, MA, USA). The sample $(25 \mu \mathrm{L})$, previously dissolved in distilled water, was allowed to react with the $\mathrm{DPPH}^{\circ}$ work solution $(175 \mu \mathrm{L})$ in the dark at room temperature $\left(23^{\circ} \mathrm{C}\right)$ for $30 \mathrm{~min}$ in a 96-well microplate (Nunc ${ }^{\mathrm{TM}}$, Thermo Fisher Scientific Inc., USA). Then, the absorbance was measured at $515 \mathrm{~nm}$ and a blank was taken with distilled water (A0). The inhibition percentage (I) of the sample was calculated using Equation (4), and Trolox was used as a standard to prepare a calibration curve $\left(0.0075-0.075 \mathrm{mg} / \mathrm{mL}, \mathrm{y}=1176.3 \mathrm{x}-1.093, \mathrm{R}^{2}=0.999\right)$. The results were expressed as milligrams of Trolox equivalent per gram of dry extract (mg TE/g DE). Three independent analyses were performed in each of the triplicate extracts obtained for each different methodology.

$$
I(\%)=\left[\left(\text { Abs }_{A 0}-\text { Abs }_{\text {sample }}\right) \div \mathrm{Abs}_{\mathrm{A} 0}\right] \times 100
$$

where $\mathrm{Abs}_{\mathrm{A} 0}$ is the absorbance of blank, and Abs sample is the absorbance of the reaction between the sample and the radicals.

\subsubsection{The Oxygen Radical Absorbance Capacity Assay (ORAC)}

Was performed in a black 96-well microplate (Nunc, Denmark), following the method described by Dávalos et al. [24] with some modifications. The reaction was carried out in a $75 \mathrm{mM}$ phosphate buffer ( $\mathrm{pH} 7.4)$, with a final reaction mixture of $200 \mu \mathrm{L}$. The sample $(20 \mu \mathrm{L})$, previously dissolved in distilled water and fluorescein $(120 \mu \mathrm{L} ; 70 \mathrm{nM}$, final concentration in well) solution, was placed in the well of the microplate. A blank (FL + AAPH) using phosphate buffer instead of the antioxidant solution (Trolox) and eight calibration solutions ((1-8 $\mu \mathrm{M}$ of Trolox, final concentration in well), $\left.y=1.39 \times 10^{6} x+1.61 \times 10^{7}, R^{2}=0.995\right)$ as antioxidant was also carried out in each assay. The mixture was preincubated for $10 \mathrm{~min}$ at $37^{\circ} \mathrm{C}$. AAPH solution $(60 \mu \mathrm{L} ; 12 \mathrm{mM}$, final concentration in well) was added rapidly using a multichannel pipet. The microplate was immediately placed in the reader, and the fluorescence recorded at intervals of $1 \mathrm{~min}$ over a period of $80 \mathrm{~min}$. A multidetector plate reader (Synergy H1, Biotek, Winooski, Vermont, USA) with $485 \mathrm{~nm}$ excitation and $520 \mathrm{~nm}$ emission filters was used. The equipment was controlled by the Gen5 Biotek software version 3.04. AAPH and Trolox 
solutions were prepared daily, and fluorescein was diluted from a stock solution (1.17 mM) in $75 \mathrm{mM}$ phosphate buffer ( $\mathrm{pH}$ 7.4). Antioxidant curves (fluorescence versus time) were first normalized to the curve of the blank corresponding to the same assay by multiplying original data by the factor fluorescence blank, $t=0$ /fluorescence control, $t=0$. From the normalized curves, the area under the fluorescence decay curve (AUC) was calculated according to the trapezoidal method (Equation (5)):

$$
A U C=\sum_{i=1}^{i=n-1}\left(\frac{f_{i}+f_{i+1}}{2}\right) *\left(t_{i+1}-t_{i}\right)
$$

where $f_{i}$ is the fluorescence at reading $i$, and $t_{i}$ is the time (minutes) at reading $i$.

The final AUC values were calculated by subtracting the AUC of the blank from all the results. Final ORAC-FL values were obtained by interpolating in the standard curve, and were expressed as $\mathrm{mg}$ of Trolox equivalents/g of dry extract (mg TE/g DE). Three independent analyses were performed in each of the triplicate extracts obtained for each different methodology.

\subsection{Statistical Analysis}

Results were presented as the average \pm standard deviation of three independent extractions $(n=3)$. The normality of data distribution was tested by Shapiro-Wilk test, the homogeneity of variances by Levene's test, and the significance of the differences between extracts was tested by the one-way analysis of variance (ANOVA). The null hypothesis that all means are equal was rejected when the difference between means was $p<0.05$. Following the ANOVA, tests of multiple comparisons were done at those statistically significant variables using the Tukey's post-hoc test (homogeneity of variance was assumed) at the $p<0.05$ significance level. All this statistical analysis was performed using SPSS version 23. Additionally, the principal component analysis (PCA) using Statgraphics Centurion XVII software was performed on the data set after normalization, and factor analysis was performed in order to reduce and explain the variability of the data. The Varimax method was used to produce orthogonal transformations to the reduced factors as to better identify the high and low correlations.

\section{Results and Discussion}

Four different antioxidant polyphenolic-rich extracts were prepared from low-calibre and non-compliant Saco variety cherries, aiming to choose the best methodology for developing added-value ingredients with antioxidant activity, since, commonly, these non-commercial traditional varieties contain more BCs than other exotic varieties that have more production yield [4,25]. The different hydro-alcoholic antioxidant extracts were further evaluated in terms of phenolic compounds composition and antioxidant capacity using chemical in vitro assays.

\subsection{Extractive Yield}

The main concern of extraction was to obtain the BCs of interest and to maximize the yields of extraction, while minimizing the concentration of undesirable compounds, such as sugars and proteins, that could interfere on the extract stability and quality. Several factors may affect the extraction efficiency being the most important: Solvent, the ratio between mass and solvent, as well as temperature and $\mathrm{pH}$. Since one of the main purposes of this work was to produce extracts, by the application of four different methodologies, following the evaluation of their bioactivities, the variables regarding type of solvent and ratio were fixed. For that, a mixture of water:ethanol $(50: 50, v / v)$ was selected, because (i) these are food grade solvents, and thus are considered to be safe for the consumer even if not completely removed from the final ingredient, (ii) are environmentally friendly, (iii) could be reused in the process, and finally, (iv) this mixture is one of the most common mixtures of solvents used to produce extracts rich in BCs [17]. The extraction yield of the different Saco cherry antioxidant polyphenol-rich extracts obtained by different extraction techniques are shown in Figure 1. The MAE allowed obtaining higher extractive yields $(17.03 \pm 0.65 \% w / w)$, while the remaining extraction techniques recovery yield was between $12-13 \% w / w$ 
$(p>0.05)$. It is important to highlight that the higher extractive yield does not always mean extraction of a higher content of phenolic compounds, since some conditions may promote the extraction of other fruit matrix components solubilized according to the extraction methodology. Since the extracting solvent, the ratio, and moisture content in the fruit were the same in all extraction techniques, it can be concluded that microwave effects were responsible for the highest extractive yields $(17.03 \pm 0.65 \%)$, while the mass transfer limitation in CE, CET, and UAE caused the lowest yields $(13.41 \pm 0.48,12.66 \pm 0.79$, and $12.63 \pm 0.92 \%$, respectively). Higher yields on MAE, when compared with the conventional heat reflux method (CET), could be due to the homogenous heating of the microwave irradiation mechanism, which results in the temperature increasing from inside the system to the outside, leading to cell disruption and consequent phenolic compounds migration to the solvent [26]. In contrast, CET increased the temperature from outside to inside, and is not so efficient [27]. Temperature influences the extraction efficiency, since higher temperature promotes an increase of the solute solubility in the solvent, increasing the solute rate diffusion into the solvent bulk, leading to a higher mass transfer rate [28]. However, the use of high temperature in conventional extraction (CET) in this study did not increase the extractive yield when compared to conventional extraction with low temperature (CE) (from 25 to $65^{\circ} \mathrm{C}$ ). Several works revealed that the use of temperature associated with a conventional extraction helps to access a better extractive yield and, consequently, higher polyphenols content [29]. However, the effect of temperature cannot be generalized since it strongly depends on the type of compounds extracted. As reported by other authors $[30,31]$ the UAE was developed to improve the recovery of nutraceuticals in comparison to conventional solvent extraction methods, and there are several studies in phenolic compounds extraction using UAE that showed better extractive yields than conventional extraction methods [32-34]. However, in this work the UAE extractive yields were not statistically different $(p>0.05)$ from the conventional extraction (CE and CET). Extraction with ultrasonic power occurs due to cell disruption, which means that the mass transfer is intensified due to solvent penetration into plant material [35]. So, the UAE may work as a pre-treatment that helps the cells' membrane disruption, while the major benefit of microwaves is the homogenous, rapid, and efficient heating of the system, which results in the expansion and rupture of cell walls, increasing solvent penetration. Similar results to this study were observed in cherry laurel extracts by Karabegović, Stojičević, Veličković, Todorović, Nikolić, and Lazić [26], who reported that MAE had highest extraction yields, followed by UAE and conventional extraction $\left(65^{\circ} \mathrm{C}\right.$ during $\left.15 \mathrm{~min}\right)$. However, this study showed lower yield extractions when compared with our results, and this might be due to lower extraction time, lower potency and frequency used, as well as the different extraction solvent (methanol). The lowest extractive yield obtained by CE was also expected, because MAE and UAE were created in order to improve the recovery of nutraceuticals in comparison to conventional solvent extraction methods [36]. The enhancement of extraction with ultrasonic power is due to the intensification of mass transfer and solvent penetration into plant material, as well as cell disruption [35], while a major benefit from microwaves is the rapid, efficient, and homogeneous heating of the total extraction system volume which also results in the expansion and rupture of cell walls and increased solvent penetration [37].

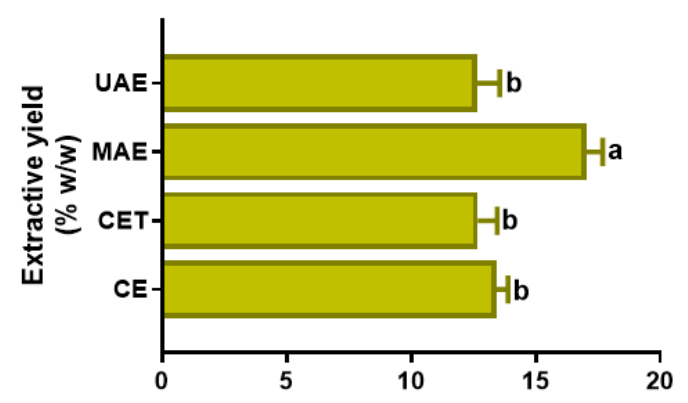

Figure 1. Extractive yield $(\% w / w)$ obtained by different extraction techniques from non-compliant Saco cherry. Different letters mean significant differences between extraction techniques, determined by Tuckey's test $(p<0.05)$. 


\subsection{Total Phenolic Content and Total Anthocyanins}

Phenolic compounds are widely distributed in the plant kingdom, such as in cherries, which are widely known for their biological activities. These compounds offer potential health benefits, especially due to the antioxidant activity [38]. The antioxidant extracts were characterized in terms of total phenolic content (TPC) and for total anthocyanins content (TAC). Table 2 shows the results of the TPC, varied between $8.75 \pm 0.81$ and $12.65 \pm 0.81 \mathrm{mg} \mathrm{GAE} / \mathrm{g}$ of $\mathrm{DE}$, and the TAC, varied between $1.76 \pm 0.06$ and $2.78 \pm 0.18 \mathrm{mg} \mathrm{Cy}$-3-glu/g DE. The extracts with the highest TPC were obtained in MAE, followed by CE $>$ UAE $>$ CET, without significant differences between UAE and CET $(p>0.05)$. The MAE was shown to be able to generate extracts with higher values of TPC, while CE showed the lowest values. Likewise, many researchers have confirmed the MAE efficiency for phenolic compounds extraction compared to traditional extraction techniques [26,39]. Since it was already mentioned that the higher yields obtained with MAE can be related to the use of more homogeneous heating [26]. However, thanks to this effect, this technology provides a higher yield of other compounds present in the matrix, and not only a selective extraction of polyphenols [40]. Anthocyanins are present in sweet cherry and are attributed to its higher antioxidant activity compared to other classes of phenolic compounds [41]. The anthocyanins are unstable in neutral or alkaline conditions, so the addition of lower acid quantity was beneficial for the anthocyanins extraction, but can negatively influence other phenolic groups, such as chlorogenic acids and flavanols [42,43]. The CET and MAE extracts showed higher values of TAC $2.78 \pm 0.18$ and $2.53 \pm 0.13 \mathrm{mg} \mathrm{Cy}-3-\mathrm{glu} / \mathrm{g}$ DE $(p>0.05)$, respectively. Meanwhile, the CE $(1.93 \pm 0.21 \mathrm{mg} \mathrm{Cy-3-glu/g} \mathrm{DE})$ and UAE (1.76 $\pm 0.06 \mathrm{mg}$ Cy-3-glu/g DE) showed the lower TAC $(p>0.05)$. Nevertheless, the heating created in MAE compared to conventional heating (CET), MAE had several advantages, like higher heating rate and purity of the final product, shorter extraction time, and lower power energy needed to run the extraction process [40].

Table 2. The Total Phenolic (TPC) and Total Anthocyanins (TAC) Content in Saco cherry extracts. Values are represented by the average \pm standard deviation. Different letters mean significant differences between extraction techniques, determined by Tukey's test $(p<0.05)$. CE: Conventional extraction; CET: Conventional extraction with high temperature; MAE: Microwaves-assisted extraction; UAE: Ultrasound-assisted extraction.

\begin{tabular}{ccc}
\hline $\begin{array}{c}\text { Saco Cherry } \\
\text { Extracts }\end{array}$ & $\begin{array}{c}\text { TPC } \\
(\mathbf{m g ~ G A E} / \mathbf{g} \text { DE) }\end{array}$ & $\begin{array}{c}\text { TAC } \\
\text { (mg Cy-3-glu/g DE) }\end{array}$ \\
\hline CE & $8.75 \pm 0.81^{\mathrm{b}}$ & $1.93 \pm 0.21^{\mathrm{b}}$ \\
CET & $7.11 \pm 0.33^{\mathrm{c}}$ & $2.78 \pm 0.18^{\mathrm{a}}$ \\
MAE & $12.65 \pm 0.81^{\mathrm{a}}$ & $2.53 \pm 0.13^{\mathrm{a}}$ \\
UAE & $7.16 \pm 0.81^{\mathrm{c}}$ & $1.76 \pm 0.06^{\mathrm{b}}$ \\
\hline
\end{tabular}

The TPC and TAC of fruit extracts reflected the extraction yields, where MAE promoted higher content of phenolics than the other methods. However, phenolics only represented $1.26 \%$ of the total SC cherry extract. This result can be related to other compounds simultaneously extracted, which account for the total extract mass. Compounds like sugars, polysaccharides, minerals, organic acids, soluble and insoluble fibres (lignin, cellulose, hemicellulose, etc.) are also extracted by the different extraction methods. Folin-Ciocalteu reagent lacking specificity can also interact with the aforementioned molecules, since it is a reaction based on electron-transfer, reducing not only polyphenols, but also sugars and proteins [44], which at the end can lead to some interference in the final measurements [45,46]. Moreover, this method is a total quantification, so it only provides an estimate of total polyphenols content present, therefore a detailed analysis of individual phenolic compounds was performed by LC-ESI-QqTOF-HRMS, and the most abundant were quantified by HPLC-DAD. 


\subsection{Phenolic Compounds Profile of Antioxidant Extracts}

\subsubsection{Identification of Major Phenolic Compounds by LC-ESI-QqTOF-HRMS}

The analysis by LC-ESI-QqTOF-HRMS allowed a full characterization of the phenolic compounds and the identification of 5 chemical classes of phenolic compounds in Saco cherry extracts, including hydroxycinnamic acids, hydroxybenzoic acids, flavanols, flavonols, and anthocyanins. Thus, around 40 phenolic compounds were identified respectively on Saco cherry extracts (Table 3). The main phenolic acids identified were hydroxycinnamic acids, of which chlorogenic acids (CGAs), were widely distributed in Saco cherry. The 3 main compounds belonging to CGAs were 3-caffeoylquinic, 4-caffeoylquinic, and 5-caffeoylquinic acids. They had a molecular ion $[\mathrm{M}-\mathrm{H}]^{-}$at $\mathrm{m} / \mathrm{z} 353$, which was consistent with the molecular formula of $\mathrm{C}_{16} \mathrm{H}_{18} \mathrm{O}_{9}$. This group of compounds was mainly found in the cherry exotic varieties, as reported by previous studies [1,5], and in Portuguese varieties, as reported by Gonçalves et al. [47] and Serra, Duarte, Bronze, and Duarte [4]. However, Matias, Rosado-Ramos, Nunes, Figueira, Serra, Bronze, Santos, and Duarte [8] only detected 3-caffeoylquinic (neochlorogenic acid) by LC-MS/MS analysis in a (Poly)phenol-Rich Extract obtained by CE with EtOH:H2O (1:1 v/v), for $2 \mathrm{~h}$, under continuous agitation $(200 \mathrm{rpm})$ followed by an adsorption process with Amberlite ${ }^{\circledR}$ XAD-16. The esterification of some hydroxycinnamic acids can occur at different positions of quinic acid moiety, resulting in four positional isomers. The fragment at m/z 191 found in compounds from this class corresponds to the loss of quinic acid.

Peaks with the $[\mathrm{M}-\mathrm{H}]^{-}$at $\mathrm{m} / \mathrm{z} 337$ were identified as coumaroylquinic acids (CoQAs) [48]. In particular, 3-CoAs and 4-CoAs were found in Saco cherry antioxidant polyphenol-rich extracts and showed the typical fragments of the $p$-coumaric acid m/z 163 and m/z 119 [49] and the loss of quinic acid. Moreover, other classes of CGAs were found: Feruloylquinic acids (FQAs) with a negative molecular at $[\mathrm{M}-\mathrm{H}]^{-} \mathrm{m} / \mathrm{z} 367$, and diCQAs with a negative molecular at $[\mathrm{M}-\mathrm{H}]^{-} \mathrm{m} / \mathrm{z} 515$. A total of 23 hydroxycinnamic acids were identified in Saco extracts, showing that this class predominates in this fruit, being that these data are supported by other studies performed in the cherries from this variety $[4,8,41,47]$. Since it has been recognized that CGAs can have health benefits, these findings in the Saco cherry extracts provide insight into the knowledge of the profile of these phenolic compounds group in sweet cherry [50].

Regarding hydroxybenzoic acids, SC cherry extracts present 5 compounds. The protocatechuic acid and one derivative were found with a $\mathrm{m} / \mathrm{z} 315$ were observed, and in the MS ${ }^{2}$ experiments of the derivative of protocatechuic acid gave a base peak at $\mathrm{m} / \mathrm{z} 153$, corresponding to protocatechuic acid aglycone that corresponds to a loss of $162 \mathrm{Da}$ [5]. One signal at $\mathrm{m} / \mathrm{z} 299$ gave a base peak in the fragmentation spectra at $\mathrm{m} / \mathrm{z} 137$, which is indicative of the presence of a hydroxybenzoic acid residue. The peak 32 showed a molecular negative ion at $\mathrm{m} / \mathrm{z} 329$, which fragmented in the $\mathrm{MS}^{2}$ experiments giving a base peak at $\mathrm{m} / \mathrm{z} 167$, suggesting the presence of a vanillic acid residue. The absence of sugar fragmentation evidence prompts us to tentatively identify this compound as vanillic acid, but regarding the $\mathrm{m} / \mathrm{z}$, these compounds could be a vanillic acid-glycoside. These 6 hydroxybenzoic acids were already documented in sweet cherries from exotic varieties, such as Della Marca, Celeste, Bigarreau, Durone Nero, Lapins, and Moretta by Martini, Conte, and Tagliazucchi [5], and one hydroxybenzoic acid derivative was identified in Saco cherries [47]. However, compounds of this class were not reported in the Saco cherry (poly)phenol-rich extracts produced according to Matias, Rosado-Ramos, Nunes, Figueira, Serra, Bronze, Santos, and Duarte [8]. 
Table 3. LC-ESI-UHR-QqTOF-MS data of phenolic compounds in different extracts from non-compliant Saco cherry.

\begin{tabular}{|c|c|c|c|c|c|c|c|c|c|}
\hline \multirow{2}{*}{ Proposed Compound } & \multirow{2}{*}{$\begin{array}{l}\text { Molecular } \\
\text { Formula }\end{array}$} & \multirow{2}{*}{$\begin{array}{c}\mathrm{RT} \\
(\mathrm{min})\end{array}$} & \multirow{2}{*}{$\begin{array}{c}\mathrm{m} / \mathbf{z} \\
\text { calcd } \\
\text { ([M-H]-) }\end{array}$} & \multirow{2}{*}{$\begin{array}{c}\text { Error } \\
(\mathrm{mDa})\end{array}$} & \multirow{2}{*}{$\begin{array}{c}\text { Major Fragments } \\
\text { Negative MS/MS Ions } \\
(\mathrm{m} / \mathbf{z})\end{array}$} & \multicolumn{4}{|c|}{ Saco Cherry Extracts } \\
\hline & & & & & & $\mathrm{CE}$ & CET & MAE & UAE \\
\hline \multicolumn{10}{|c|}{ Hydroxycinnamic acids } \\
\hline 3-Caffeoylquinic acid cis & $\mathrm{C}_{16} \mathrm{H}_{18} \mathrm{O}_{9}$ & 7.7 & 353.1 & 1.0 & 191(100), 179(80), 135(16) & D. & D. & D. & D. \\
\hline 3-Caffeoylquinic acid trans & $\mathrm{C}_{16} \mathrm{H}_{18} \mathrm{O}_{9}$ & 7.8 & 353.1 & 1.3 & 191(100), 179(54), 135(28) & D. & D. & D. & D. \\
\hline 5-Caffeoylquinic acid trans & $\mathrm{C}_{16} \mathrm{H}_{18} \mathrm{O}_{9}$ & 8.8 & 353.1 & 1.1 & 191.05(100) & D. & D. & D. & D. \\
\hline 4-Caffeoylquinic acid trans & $\mathrm{C}_{16} \mathrm{H}_{18} \mathrm{O}_{9}$ & 9 & 353.1 & 1.2 & 173(100), 179(70), 191(40), 135(20) & D. & D. & D. & D. \\
\hline 3-Coumaroylquinic acid & $\mathrm{C}_{16} \mathrm{H}_{18} \mathrm{O}_{8}$ & 8.6 & 337.1 & 1.3 & 163.(100), 119(18), 191(10) & D. & D. & D. & D. \\
\hline 4-Coumaroylquinic acid cis & $\mathrm{C}_{16} \mathrm{H}_{18} \mathrm{O}_{8}$ & 9.8 & 337.1 & 0.6 & 173(100), 163(16), 191(15) & D. & D. & D. & D. \\
\hline 4-Coumaroylquinic acid trans & $\mathrm{C}_{16} \mathrm{H}_{18} \mathrm{O}_{8}$ & 10.2 & 337.1 & 1.1 & 173(86), 163.03(24) & D. & D. & D. & D. \\
\hline Feruloylquinic acid isomer & $\mathrm{C}_{16} \mathrm{H}_{16} \mathrm{O}_{10}$ & 6,9 & 367.1 & 1.1 & $163(18), 205(16)$ & D. & D. & D. & D. \\
\hline 3-Feruloylquinic acid cis & $\mathrm{C}_{17} \mathrm{H}_{20} \mathrm{O}_{9}$ & 8.4 & 367.1 & 0.9 & 193(100), 134(10), 149(3) & D. & D. & D. & D. \\
\hline 5-Feruloylquinic acid cis & $\mathrm{C}_{17} \mathrm{H}_{20} \mathrm{O}_{9}$ & 10.1 & 367.1 & 0.8 & 173(100) & D. & D. & N.D. & D. \\
\hline Caffeoylquinic acid-glycoside & $\mathrm{C}_{22} \mathrm{H}_{27} \mathrm{O}_{14}$ & 6.4 & 515.1 & 1.6 & $\begin{array}{c}341(35), 179(27), 335(11), 191(8), 353(6) \\
323(3)\end{array}$ & D. & D. & D. & D. \\
\hline 4,5-diCaffeoylquinic acid & $\mathrm{C}_{25} \mathrm{H}_{24} \mathrm{O}_{12}$ & 12.9 & 515.1 & 0.7 & 335(91), 191(32), 179(27), & D. & D. & N.D. & D. \\
\hline 4-Caffeoylquinic acid lactone & $\mathrm{C}_{16} \mathrm{H}_{16} \mathrm{O}_{8}$ & 10.5 & 335.1 & 1.0 & 161(77), 191(15), 135(15) & D. & D. & D. & D. \\
\hline 4-Coumaroylquinic acid lactone & $\mathrm{C}_{16} \mathrm{H}_{16} \mathrm{O}_{7}$ & 12.2 & 319.0 & 1.1 & 145(100), 119(14), 163(9), 173(4) & D. & D. & D. & D. \\
\hline$p$-Coumaric acid derivative & $\mathrm{C}_{9} \mathrm{H}_{8} \mathrm{O}_{3}$ & 6.9 & 163.0 & 0.8 & $119(100)$ & D. & D. & D. & D. \\
\hline Coumaroyl hexose & $\mathrm{C}_{15} \mathrm{H}_{18} \mathrm{O}_{8}$ & 8.2 & 325.1 & 0.8 & $145(100), 163(18), 265(4.5), 187(3), 205(3)$ & D. & D. & D. & D. \\
\hline Caffeic acid-glycoside & $\mathrm{C}_{15} \mathrm{H}_{17} \mathrm{O}_{9}$ & 8.7 & 341.1 & 0.9 & 179(100), 135(13) & D. & D. & D. & D. \\
\hline Caffeoyl alcohol 3/4-o-hexoside & $\mathrm{C}_{15} \mathrm{H}_{19} \mathrm{O}_{8}$ & 8.5 & 327.1 & 0.7 & $165(100), 121(2)$ & D. & D. & D. & D. \\
\hline Feruloyl hexose & $\mathrm{C}_{16} \mathrm{H}_{19} \mathrm{O}_{9}$ & 9.6 & 355.1 & 1.5 & 175(100), 193(46), 295(8) & D. & D. & D. & D. \\
\hline Sinapoyl hexose & $\mathrm{C}_{17} \mathrm{H}_{21} \mathrm{O} 10$ & 8.1 & 385.1 & 1.1 & 223(100), 208(12) & D. & D. & D. & D. \\
\hline \multicolumn{10}{|c|}{ Flavanols } \\
\hline Epicatechin-3-gallate & $\mathrm{C}_{22} \mathrm{H}_{18} \mathrm{O}_{10}$ & 12.8 & 441.1 & & $395(100), 263(81), 441(6)$ & D. & D. & D. & D. \\
\hline \multicolumn{10}{|c|}{ Flavonols } \\
\hline Quercetin-7-O-glucoside-3-O-rutinoside & $\mathrm{C}_{33} \mathrm{H}_{40} \mathrm{O}_{21}$ & 10.5 & 771.2 & 1.4 & $609(100)$ & D. & D. & D. & D. \\
\hline Kaempferol-3-glucoside & $\mathrm{C}_{21} \mathrm{H}_{20} \mathrm{O}_{11}$ & 17.6 & 447.1 & 1.2 & $285(92)$ & D. & N.D. & D. & N.D. \\
\hline
\end{tabular}


Table 3. Cont.

\begin{tabular}{|c|c|c|c|c|c|c|c|c|c|}
\hline \multirow{2}{*}{ Proposed Compound } & \multirow{2}{*}{$\begin{array}{l}\text { Molecular } \\
\text { Formula }\end{array}$} & \multirow{2}{*}{$\begin{array}{c}\text { RT } \\
(\min )\end{array}$} & \multirow{2}{*}{$\begin{array}{c}\mathbf{m} / \mathbf{z} \\
\text { calcd } \\
\text { ([M-H]-) }\end{array}$} & \multirow{2}{*}{$\begin{array}{c}\text { Error } \\
(\mathrm{mDa})\end{array}$} & \multirow{2}{*}{$\begin{array}{c}\text { Major Fragments } \\
\text { Negative MS/MS Ions } \\
(\mathrm{m} / \mathrm{z})\end{array}$} & \multicolumn{4}{|c|}{ Saco Cherry Extracts } \\
\hline & & & & & & CE & CET & MAE & UAE \\
\hline Kaempferol-3-rutinoside & $\mathrm{C}_{27} \mathrm{H}_{30} \mathrm{O}_{16}$ & 12.5 & 593.1 & 1.7 & $285(29)$ & D. & D. & D. & D. \\
\hline \multicolumn{10}{|c|}{ Other flavonoids } \\
\hline \multicolumn{10}{|c|}{ Hydroxybenzoic acids } \\
\hline Protocatechuic acid-glycoside & $\mathrm{C}_{13} \mathrm{H}_{15} \mathrm{O}_{9}$ & 6.3 & 315.1 & 0.6 & 109(5), 153(100) & D. & D. & D. & D. \\
\hline Hydroxybenzoic acid-glycoside & $\mathrm{C}_{13} \mathrm{H}_{16} \mathrm{O}_{8}$ & 6,3 & 299.1 & 0.9 & 137(100) & D. & D. & D. & D. \\
\hline Hydroxybenzoyl hexose & $\mathrm{C}_{13} \mathrm{H}_{16} \mathrm{O}_{8}$ & 7.4 & 299.1 & 1.0 & 137(29), 179(20), 239(14) & D. & D. & D. & D. \\
\hline Vanillic acid-glycoside & $\mathrm{C}_{14} \mathrm{H}_{17} \mathrm{O}_{9}$ & 7.2 & 329.1 & 0.6 & $167(100)$ & D. & D. & D. & D. \\
\hline \multicolumn{10}{|c|}{ Anthocyanins } \\
\hline Cyanidin-3-glucoside & $\mathrm{C}_{21} \mathrm{H}_{21} \mathrm{O}_{11}$ & 12.3 & 449.2 & 0.1 & $287(100)$ & D. & D. & D. & D. \\
\hline Cyanidin-3-rutinoside & $\mathrm{C}_{27} \mathrm{H}_{31} \mathrm{O}_{15}$ & & 595.1 & 0.6 & $287(100), 449(14)$ & D. & D. & D. & D. \\
\hline Peonidin-3-glucoside & $\mathrm{C}_{22} \mathrm{H}_{23} \mathrm{O}_{11}$ & 12.4 & 463.1 & 0.6 & $301(100)$ & D. & D. & D. & D. \\
\hline Pelargonidin-3-rutinoside & $\mathrm{C}_{27} \mathrm{H}_{31} \mathrm{O}_{14}$ & 14 & 579.1 & 1.3 & 271(100), $433(20)$ & D. & N.D. & D. & D. \\
\hline
\end{tabular}

Note: N.D, non-detectable; D., detectable; RT, retention time; m/z calcd ([M-H] $\left.]^{-}\right)$: Experimental values. 
Epicatechin-3-gallate ( $\mathrm{m} / \mathrm{z} 441.1)$, previously described in cherries, was the only compound identified within the flavanols class. This fact was not surprising, since Gonçalves, et al. [51] observed that the compounds from the same class decreased in Saco variety during storage time. Additionally, Acero, Gradillas, Beltran, García, and Mingarro [1] did not find any compound from flavanols in sweet cherries cultivated in Spain. On the other hand, Martini, Conte, and Tagliazucchi [5] identified 12 more flavanols in cherry exotic varieties, including procyanidins, and Serra, Duarte, Bronze, and Duarte [4] identified two flavanols in Saco cherries ((+)-catechin and (-)-epicatechin). Furthermore, Matias, Rosado-Ramos, Nunes, Figueira, Serra, Bronze, Santos, and Duarte [8] reported the presence of (+)-catechin and procyanidin B2 in antioxidants extracts from Saco cherry produced by recovery (poly)phenols from extracts by adsorption process, although, Gonçalves, Rodrigues, Santos, Alves, and Silva [17] did not identify any flavanols in Saco cherry hydro-alcoholic extracts.

Among flavonols, only 3 derivatives were identified: Kaempferol-3-rutinoside, kaempferol-3-glucoside, and quercetin derivative, which were reported previously by Martini, Conte, and Tagliazucchi [5] in exotic varieties and Portuguese varieties, for instance, Saco sweet cherry for Gonçalves, Bento, Silva, and Silva [47], and in Saco cherry polyphenol-rich extracts $[8,17]$. Regarding anthocyanins, a total of 5 were identified in antioxidant polyphenol-rich extracts: Cyanidin-3-glucoside, cyanidin-3-rutinoside, peonidin-3-rutinoside, peonidin-3-glucoside, and pelargonidin-3-glucoside. These anthocyanins had been already identified in the Saco variety [47] and in polyphenol-rich extracts produced from Saco cherry [17], being that these anthocyanins are the most reported in cherries, in spite of the variety. All the extraction methodologies showed to be able to recover all phenolic compounds except on MAE extracts, where three of the hydroxycinnamic acids were not detected. Furthermore, only with CET was it not possible to recover all the mainly identified anthocyanins in sweet cherry, because pelargonidin-3-rutinoside was not present in this extract. Elevated temperatures have been reported to improve the efficiency of extraction due to enhanced diffusion rate and solubility of analytes in solvents. However, elevated temperature for long periods may increase the anthocyanins degradation rate because the degradation rate of anthocyanins is time and temperature-dependent. Therefore, high-temperature in short-time extraction conditions and processing treatments have been used successful in retarding anthocyanin degradation in fruits. This could explain the recovery of all anthocyanins in MAE, but not in CET. For instance, research carried out by Ju and Howard [51] reports that optimal MAE conditions differed for anthocyanins and phenolic acids, especially in terms of temperature and irradiation time, so lower temperature $\left(<60^{\circ} \mathrm{C}\right)$ and shorter time were more convenient for anthocyanins extraction. On the other hand, for phenolic acids, higher extraction yield at higher temperatures $\left(70^{\circ} \mathrm{C}\right)$ and longer irradiation time $(10$ min) was observed.

\subsubsection{Quantification of Phenolic Compounds by HPLC-DAD}

The individual phenolic compounds of Saco cherry extracts quantified using HPLC-DAD are summarized in Table 4. The extracts, despite the differences observed in the amounts of each phenolic compound, exhibited similar chromatographic profile, as expected, due to the previous identification reported (Section 3.3.1). The anthocyanins were the most representative class with the highest amount present in cherry extracts being cyanidin-3-rutinoside, the major compound identified in all extracts represented, approximately $70 \%$ of the total content of anthocyanins and $40 \%$ of total phenolic compounds quantified. The CET and MAE extracts showed the highest amount of this anthocyanin $(p>0.05), 2.54 \pm 0.16$ and $2.46 \pm 0.03 \mathrm{mg} / \mathrm{DE}$, respectively). However, MAE allowed for the recovery of higher amounts of cyanidin-3-glucoside $(1.14 \pm 0.01 \mathrm{mg} / \mathrm{g} \mathrm{DE})$, peonidin-3-rutinoside $(0.16 \pm 0.03 \mathrm{mg} / \mathrm{g} \mathrm{DE})(p>0.05)$, and pelargonidin-3-rutinoside $(0.06 \pm 0.05 \mathrm{mg} / \mathrm{g} \mathrm{DE})$ than the other extraction methodologies. Similar results were reported by other authors where the main anthocyanins in sweet cherry were cyanidins, peonidin-3-rutinoside, and pelargonidin-3-rutinoside [3]. Therefore, our data is in accordance with previous works on Saco cherries, where Gonçalves, Bento, Silva, and Silva [47], and Serra, Duarte, Bronze, and Duarte [4] reported cyanidin-3-O-rutinoside and 
cyanidin-3-O-glucoside as the main anthocyanins present in sweet cherries from Saco variety and also quantified the two anthocyanins reported in Saco cherry. On the other hand, a study performed by Gonçalves, Rodrigues, Santos, Alves, and Silva [17] reported that a Saco cherry extract produced with conventional extraction followed by a C18 solid-phase extraction (SPE) is rich in the same anthocyanins, however, the amount of anthocyanins is higher because SPE allows purification and consequently increased extract concentration. Additionally, a (poly)phenol-rich extract was produced by Matias, Rosado-Ramos, Nunes, Figueira, Serra, Bronze, Santos, and Duarte [8] with a two-step separation process: First encompasses a solid-liquid CE followed by an adsorption process, showed higher amount of cyanidin-3-rutinoside, cyanidin-3-glucoside, and peonidin-3-glucoside, however, pelargonidin-3-rutinoside was not present. The great diversity of phenolic compounds found in Saco cherry highlights the importance to valorise non-compliant fruit because although it does not have acceptable parameters for direct sale in fresh food chains, it is still rich in BCs such as phenolic compounds. Furthermore, the valorisation of the regional fruit variety supports the preventing of habitat loss due to urbanization and provides a boost to the local bioeconomy by promoting the commercialization of new products deriving from regional varieties, and thereby reduces the $C$ footprint in the environment due to the valorisation of food losses [2].

Table 4. Quantification of main phenolic compounds (mg/g DE (Dry extract)) in different extracts from Saco cherry by HPL-DAD. Values are represented by the average \pm standard deviation. Different letters mean significant differences between extraction techniques, determined by Tukey's test $(p<0.05)$.

\begin{tabular}{|c|c|c|c|c|}
\hline \multirow{2}{*}{ Phenolic Compounds } & \multicolumn{4}{|c|}{ Saco Cherry Extracts } \\
\hline & $\mathrm{CE}$ & CET & MAE & UAE \\
\hline \multicolumn{5}{|c|}{ Hydroxycinnamic acids } \\
\hline 3-Caffeoylquinic acid & $0.54 \pm 0.05^{\mathrm{c}}$ & $0.87 \pm 0.02^{b}$ & $0.99 \pm 0.07^{\mathrm{a}}$ & $0.54 \pm 0.00^{\mathrm{c}}$ \\
\hline 5-Caffeoylquinic acid & $0.40 \pm 0.08^{a b}$ & $0.26 \pm 0.05^{c}$ & $0.38 \pm 0.01^{b}$ & $0.46 \pm 0.01^{\mathrm{a}}$ \\
\hline 4-Caffeoylquinic acid & B.Q.L & $0.06 \pm 0.03^{b}$ & $0.15 \pm 0.04^{\mathrm{a}}$ & $0.09 \pm 0.02^{a}$ \\
\hline 4,5-dicaffeoylquinic acid & $0.08 \pm 0.02^{\mathrm{a}}$ & $0.08 \pm 0.00^{\mathrm{a}}$ & N.D & $0.02 \pm 0.00^{b}$ \\
\hline Caffeic acid & B.D.L & $0.09 \pm 0.03^{a}$ & $0.08 \pm 0.02^{\mathrm{a}}$ & B.Q.L \\
\hline$p$-coumaroylquinic acid & $0.47 \pm 0.20^{c}$ & $1.03 \pm 0.05^{a}$ & $0.63 \pm 0.00^{b}$ & $0.39 \pm 0.00^{d}$ \\
\hline$p$-coumaric acid & $0.20 \pm 0.03^{c}$ & B.Q.L & $0.62 \pm 0.05^{\mathrm{a}}$ & $0.31 \pm 0.00^{b}$ \\
\hline \multicolumn{5}{|c|}{ Flavan-3-ols } \\
\hline (-)-Epicatechin-3-gallate & B.Q.L & B.Q.L & $0.03 \pm 0.08^{\mathrm{a}}$ & B.Q.L \\
\hline \multicolumn{5}{|c|}{ Flavonols } \\
\hline Quercetin-3-rutinoside & $0.42 \pm 0.63^{\mathrm{a}}$ & $0.24 \pm 0.02^{b}$ & $0.14 \pm 0.00^{\mathrm{c}}$ & $0.05 \pm 0.01^{d}$ \\
\hline Kaempferol-3-glucoside & $0.07 \pm 0.00^{\mathrm{a}}$ & N.D. & $0.06 \pm 0.02^{b}$ & N.D. \\
\hline Quercetin & B.D.L. & B.D.L. & $0.12 \pm 0.00^{\mathrm{a}}$ & B.D.L. \\
\hline \multicolumn{5}{|c|}{ Anthocyanins } \\
\hline Cyanidin-3-rutinoside & $2.13 \pm 0.25^{b}$ & $2.54 \pm 0.16^{\mathrm{a}}$ & $2.46 \pm 0.13^{\mathrm{a}}$ & $2.21 \pm 0.19^{b}$ \\
\hline Cyanidin-3-glucoside & $0.58 \pm 0.04^{\mathrm{c}}$ & $0.87 \pm 0.11^{b}$ & $1.14 \pm 0.01^{\mathrm{a}}$ & $0.54 \pm 0.06^{c}$ \\
\hline Peonidin-3-rutinoside & $0.08 \pm 0.00^{b}$ & $0.07 \pm 0.05^{b}$ & $0.16 \pm 0.03^{\mathrm{a}}$ & $0.06 \pm 0.01^{b}$ \\
\hline Pelargonidin-3-rutinoside & $0.06 \pm 0.01^{\mathrm{a}}$ & N.D. & $0.06 \pm 0.05^{\mathrm{a}}$ & $0.04 \pm 0.00^{\mathrm{a}}$ \\
\hline
\end{tabular}

Regarding the hydroxycinnamic acids in SC cherry extracts, 3-caffeoylquinic acid, 5-caffeoylquinic acid, $p$-coumaroylquinic acid, and $p$-coumaric acid were the major compounds in extracts. These compounds were found in greater quantities in extracts obtained by MAE $(0.99 \pm 0.07,0.38 \pm$ $0.01,0.63 \pm 0.00$, and $0.62 \pm 0.05 \mathrm{mg} / \mathrm{g} \mathrm{DE}$, respectively) and CET $(0.87 \pm 0.02,0.26 \pm 0.05$, and 1.03 \pm 0.05 , respectively), with the exception of 5-caffeoylquinic acid (UAE recovery the higher amount $(0.46 \pm 0.01 \mathrm{mg} / \mathrm{g} \mathrm{DE}))$ and $p$-coumaric acid (the concentration in CET was below the quantification limit). Nevertheless, extracts produced by Matias, Rosado-Ramos, Nunes, Figueira, Serra, Bronze, Santos, and Duarte [8], and Gonçalves, Rodrigues, Santos, Alves, and Silva [17] with two-step separation process also had more quantity of hydroxycinnamic acids (likewise anthocyanins), but they present less diversity of compounds.

The epicatechin-3-gallate was only detected in MAE extract $(0.02 \pm 0.08 \mathrm{mg} / \mathrm{g} \mathrm{DE})$, and among the flavonols, the higher amount was found in CE extract with $0.42 \pm 0.63 \mathrm{mg} / \mathrm{g}$ DE of quercetin-3-rutinoside 
and $0.05 \pm 0.00 \mathrm{mg} / \mathrm{g} \mathrm{DE}$, however, quercetin-3-glucoside was only quantified on MAE extract $(0.12 \pm 0.00 \mathrm{mg} / \mathrm{g} \mathrm{DE})$. The MAE, likewise, observed in TPC showed a higher amount of phenolic compounds.

Although HPLC-DAD analysis is a well-documented technique for polyphenols quantification, the sum of all phenolic compounds quantified was lower than those quantified by Folin-Ciocalteu assay (Table 2) for all the extracts. These differences, despite some of the minor peaks, could not be quantified, because they were under detection range given the lowest values of quantification, the use of Folin-Ciocalteu's reagent can also react with polysaccharides and proteins given an overestimation of total phenolic content [46]. Furthermore, the TPC results are expressed based in gallic acid equivalents and on HPLC results, and it is quantified with the exact amount of phenolic compound itself.

\subsection{Antioxidant Activity}

Natural antioxidants present in fruits have gained interest among the scientific community, consumers, and food industries since epidemiological studies have indicated that regular consumption of natural antioxidants is associated with a lower risk of chronic diseases and could replace synthetic antioxidants in foodstuffs [52]. To evaluate the antioxidant activity of functional extracts, different methods with different action mechanisms need to be used. Since the antioxidant capacity of food is determined by a mixture of different phenolic compounds with different action mechanisms, among which synergistic interactions are also occurring, it is necessary to combine more than one method in order to determine in vitro antioxidant capacity [53]. Stable radicals such as ABTS or DPPH are among the most popular colorimetric methods to evaluate antioxidant activity in foods. Nevertheless, ABTS applies to both hydrophilic and lipophilic antioxidant systems, whereas DPPH applies to hydrophobic systems [54]. ORAC method has been reported by different authors as a more relevant antioxidant procedure because it engages a biological radical (peroxyl) source and is a very high sensitivity method, which is mainly used to measure the activity of hydrophilic antioxidants compounds [23,55].

Data of in vitro antioxidant activity measured by ORAC, ABTS, and DPPH methods are shown in Figure 2. In Saco cherry extracts, antioxidant activity measured by $\mathrm{ORAC}, \mathrm{ABTS}^{\circ}$, and $\mathrm{DPPH}^{\circ}$ methods ranged from $35.62 \pm 4.80$ to $50.46 \pm 4.80 \mathrm{TE} / \mathrm{g} \mathrm{DE}$, from $6.73 \pm 0.38$ to $10.88 \pm 0.38 \mathrm{AAE} / \mathrm{g} \mathrm{DE}$, and from $6.66 \pm 0.32$ to $9.58 \pm 0.42 \mathrm{mg} \mathrm{TE} / \mathrm{g} \mathrm{DE}$, respectively. The SC cherry extracts had the highest antioxidant capacity and exhibited good scavenging effects on ORAC assay using MAE, presenting values of $50.46 \pm 1.58 \mathrm{mg}$ TE/g DE, followed by CE (38.34 $\pm 4.09 \mathrm{mg}$ TE/g DE), UAE (35.62 $\pm 4.80 \mathrm{mg}$ TE/g DM), and CET $(35.80 \pm 2.18 \mathrm{mg}$ TE/g DE), without significant differences $(p>0.05)$ between the last three extraction methods. The ORAC values of Saco cherry showed a high positive correlation $\left(R^{2}=0.9853\right)$ with the previous values of TPC. The values obtained by the ORAC method were much higher than the values by $\mathrm{DPPH}^{\circ}$ and $\mathrm{ABTS}^{\circ}$. Similar differences were reported in antioxidant assays of several fruit, plants, and by-products [56]. These differences probably arise from the different mechanisms involved during each methodology: Single electron transfer (SET) in the case of DPPH/ABTS, and hydrogen atom transfer (HAT) in the case of the ORAC assay [56].

Regarding $\mathrm{ABTS}^{\circ}$ assay results, the Saco cherry extracts obtained by MAE also presented higher antioxidant activity $(10.88 \pm 0.38 \mathrm{mg} \mathrm{AAE} / \mathrm{g} \mathrm{DE})$, followed by CE $(7.80 \pm 0.56 \mathrm{mg}$ AAE/g DE) and CET $(7.65 \pm 0.28 \mathrm{mg} \mathrm{AAE} / \mathrm{g} \mathrm{DE})$, and with the lowest values attributed by UAE $(6.73 \pm 0.38 \mathrm{mg} \mathrm{AAE} / \mathrm{g} \mathrm{DE})$.

The inhibition of $\mathrm{DPPH}^{\circ}$ free radicals was similar for Saco cherry extracts obtained by MAE $(9.58 \pm 0.42 \mathrm{mg} \mathrm{TE} / \mathrm{g} \mathrm{DE})$ and UAE $(9.44 \pm 0.38 \mathrm{mg} \mathrm{TE} / \mathrm{g} \mathrm{DE})(p>0.05)$, however, they had more scavenging activity than extracts obtained by the conventional methods with low and high temperature, $6.98 \pm 0.55$ and $6.66 \pm 0.32 \mathrm{mg}$ TE/g DE, respectively. In Saco cherry extracts, the $\mathrm{DPPH}^{\circ}$ method did not correlate with the TPC $\left(\mathrm{R}^{2}=0.4099\right)$. This could be due to the fact that the $\mathrm{DPPH}^{\circ}$ method used a free radical that can only be dissolved in an organic solvent and therefore evaluates hydrophobic systems [54]. The higher antioxidant activity obtained on SC cherry extracts (observed in all different antioxidant assays) through the application of MAE, could be the result of a better plant cells disruption, as reported for this methodology. As already stated, these extracts have more phenolic compounds, 
and this extraction technique makes compounds more bio-accessible, mainly anthocyanidins and flavonols, which have been reported to have more scavenging activity than most common phenolic compounds, such as phenolic acids, due to the great number of functional groups $\left(\mathrm{OH}^{-}\right)$present in their structure [41,57].

There are no specific studies about the use of non-compliant cherries to produce functional extracts with an antioxidant activity using green methodologies such as MAE and UAE. Notwithstanding, there are some studies about the antioxidant activity of Saco cherry fruit, namely Gonçalves, Bento, Silva, and Silva [47], reporting that this variety exhibited a dose-dependent effect against $\mathrm{DPPH}^{\circ}$ radical, and Serra, Duarte, Bronze, and Duarte [4] reported that Saco cherry showed higher values of ORAC than other Portuguese cherry varieties. There are also three important studies about the Saco cherry extract production reporting (1) that a polyphenol extract produced by conventional hydro-alcoholic extraction with low temperature was more active than the extract fractions obtained that followed concentration and purification with SPE column [17]; (2) the (poly)phenol-rich extract obtained by a CE with EtOH:H2O (1:1 v/v) for $2 \mathrm{~h}$ followed an adsorption process with Amberlite ${ }^{\circledR}$ XAD-16 showed a higher antioxidant activity by ORAC method, being about two-fold higher than the control (Vitamin C) [8], and (3) Serra et al. [58] reported the use of supercritical $\mathrm{CO}_{2}$ extraction followed by solvent extraction with $\mathrm{CO}_{2}: \mathrm{EtOH}(90: 10, v / v)$ and extracts revealed a great antioxidant activity. However, the differences between previous works and our results could be due to the differences in the extraction methodologies

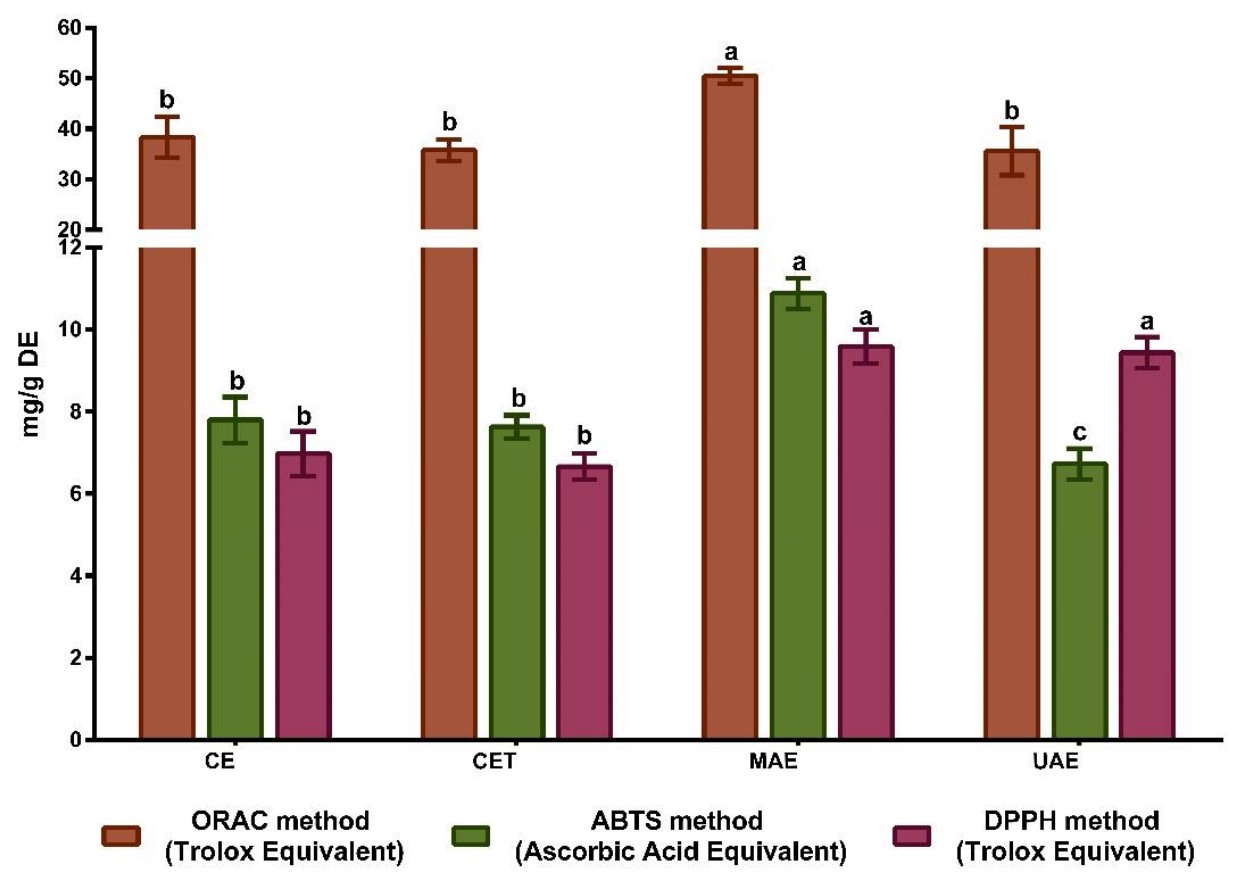

Figure 2. Antioxidant activity of different Saco cherry extracts by oxygen radical absorbance capacity (ORAC) method (expressed as mg TE (Trolox equivalent)/g DE), ABTS ${ }^{\circ}$ (2-azinobis-3-ethylbenzothiazoline-6-sulphonic acid) method (expressed as mg AAE/g DE) and DPPH ${ }^{\circ}$ (2,2-diphenyl-1-picrylhydrazyl) method (expressed as mg TE/g DE). Different letters mean significant differences between extraction techniques for each antioxidant activity assay (same colour in the graph), determined by Tukey's test $(p<0.05)$.

Overall, some of the phenolic compounds identified in Saco cherry extracts are well-documented as efficient reducing compounds and scavenging free radicals, and furthermore has been demonstrated as being more effective than other BCs in fruit. Regarding anthocyanins, several studies showed that these compounds have potential to inhibit tumour growth, slow cardiovascular diseases, and retard the ageing process due to their higher antioxidant activity. Additionally, other flavonoids 
identified in cherry extracts, such as quercetin, catechin and epicatechin, neochlorogenic acid, and chlorogenic acid are widely reported to act as powerful antioxidants and anticancer agents. Moreover, it is important to reinforce the possible presence of other non-determined reducing compounds, such as carotenoids, organic acids, and volatile compounds, which may also contribute to increasing the total antioxidant activity values obtained by chemical in vitro methods [17], and that were not determined and quantified in the antioxidant extracts produced.

Nevertheless, this relevant evidence on these fruit extracts shows the importance of valorising non-compliant fruit as natural sources of BCs, mainly antioxidant compounds, being a low-cost resource that could be used to develop natural antioxidant extracts to apply in the food industry. On the other hand, the production of natural antioxidant extracts from non-compliant fruit represents a solution with low environmental impact since it uses food that had not added-value.

\subsection{Principal Component Analysis}

In order to achieve a better overview, due to the large amount of data obtained, to distinguish the different antioxidant extracts according to their phenolic compounds content and antioxidant activity. and to identify a potential relationship between the extraction techniques applied, a principal component analysis (PCA) was performed for the Saco cherry extracts. The 20 variables considered in PCA are described in Table 5.

Table 5. Description of the 20 variables considered in principal component analysis (PCA) for Saco cherry extracts.

\begin{tabular}{cccc}
\hline \multicolumn{2}{c}{ Saco Cherry Extracts } \\
\hline $\begin{array}{c}\text { Variable } \\
\text { Number }\end{array}$ & $\begin{array}{c}\text { Variable } \\
\text { Designation }\end{array}$ & $\begin{array}{c}\text { Variable } \\
\text { Number }\end{array}$ & $\begin{array}{c}\text { Variable } \\
\text { Designation }\end{array}$ \\
\hline 1 & Total Phenolic Content & 11 & 5-Caffeoylquinic acid \\
2 & Total Anthocyanins Content & 12 & 4-Caffeoylquinic acid \\
3 & ABTS assay & 13 & 4,5-Di-O-Caffeoylquinic acid \\
4 & DPPH assay & 14 & Caffeic acid \\
5 & ORAC assay & 15 & p-coumaroylquinic acid \\
6 & Cyanidin-3-rutinoside & 16 & p-coumaric acid \\
7 & Cyanidin-3-glucoside & 17 & Epicatechin-3-gallate \\
8 & Peonidin-3-rutinoside & 18 & Quercetin-3-rutinoside \\
9 & Pelargonidin-3-rutinoside & 19 & Kaempferol \\
10 & 3-Caffeoylquinic acid & 20 & Quercetin \\
\hline
\end{tabular}

The cumulative percentage of the total variance explained by the first two components was 85.2\% (Figure 3), where the PCA bidimensional plot shows the information about samples (dots) and variables (vectors) as a data matrix. Component 1 , which described $52.44 \%$ of parameters variability, was positively influenced by almost ten variables, such as TPC, antioxidant activity (ABTS ${ }^{\circ}$ and ORAC method), 3-caffeoylquinic acid, peonidin-3-rutinoside, and pelargonidin-3-rutinoside. Component 2 , which accounted for $32.78 \%$ of the variability, received the main positive contribution from 5 -caffeoylquinic acid, antioxidant activity ( $\mathrm{DPPH}^{\circ}$ method), pelargonidin-3-rutinoside, and $p$-coumaric acid. By the analysis of the variables, it was possible to verify that the TPC is more correlated with $\mathrm{ABTS}^{\circ}$ and ORAC than $\mathrm{DPPH}^{\circ}$, and the flavonols and anthocyanins are more correlated with antioxidant activity due to their structure since they have higher antioxidant potential than other phenolics groups. MAE is represented in the positive values of the components due to a higher number and levels of anthocyanins and phenolics as well as great antioxidant activity; CET is represented in the negative values of component 2 due to a lower number of anthocyanins as well as antioxidant activity. On the positive side of component 2, it can be seen that CE and UAE, which are related with a lower amount of anthocyanins, are the main compounds in sweet cherry responsible for the high values of antioxidant activity. 


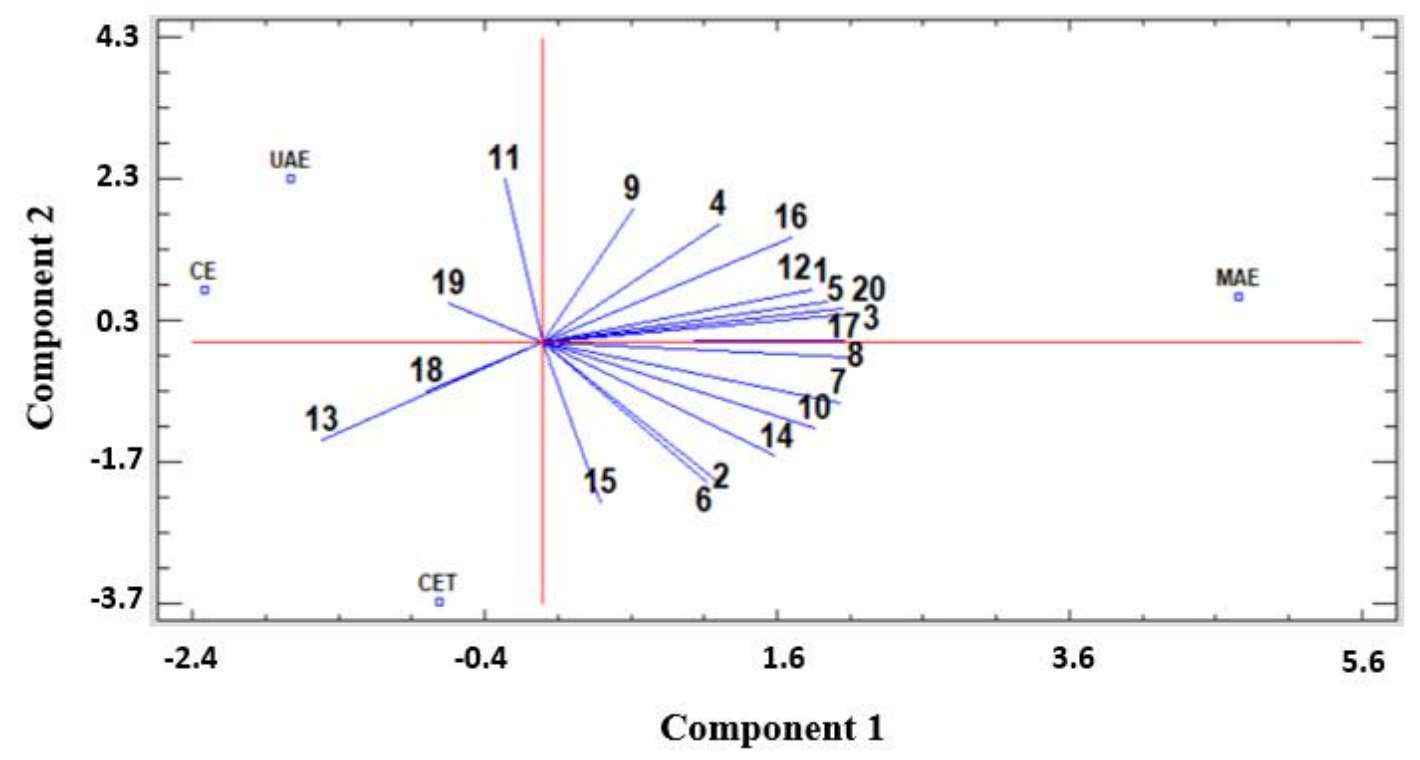

Figure 3. Principal Component Analysis (PCA) biplot for the 20 parameters analysed in Saco cherry extracts. The first component explained $52.44 \%$ of the variance and the second component explained $32.78 \%$.

The PCA confirms all the results discussed previously, concluding that the use of MAE was the most efficient and the use of CET using $65^{\circ} \mathrm{C}$ presented the lowest values of phenolic compounds as well as antioxidant activity. These results are in line with expectations since the exposure of anthocyanins to high temperatures over long periods causes their degradation. Therefore, application of MAE for $15 \mathrm{~min}$ allowed us to obtain polyphenol-rich extracts with better antioxidant capacity than UAE applied for $30 \mathrm{~min}$, or CE and CET for $30 \mathrm{~min}$. The advantages of MAE are that high-efficiency extraction can be done using only the water content present in cherry, while simultaneously reducing extraction time. Besides, easy maintenance of extraction vessels, enhancement of recovery and repeatability, and the possibility of simultaneous extraction of multiple samples are also better with MAE than with CE techniques and UAE [40,59].

\section{Conclusions}

In the present work, different extraction methodologies (CE, CET, MAE, and UAE) were applied to develop polyphenolic-rich extracts aiming at developing new functional ingredients with antioxidant activity using non-compliant sweet cherry. The results showed that MAE is better than conventional extraction methods (CE and CET) and the other green methodology applied (UAE) to obtain functional extracts from non-compliant Saco cherry. With this green solid-liquid extraction technique, it was possible to obtain a polyphenolic-rich extract with the highest ABTS, DPPH, and ORAC values. The main phenolic compounds identified included neochlorogenic acid, $p$-coumaric, quercetin-3-rutinoside, and anthocyanins, namely cyanidin-3-rutinoside. The current results proved that the non-compliant Saco cherry are indeed of high value to be used as sources of functional ingredients extraction, which might be useful for human consumption. The application of new alternative solutions for the valorisation of non-compliant cherries brings value to the fruit supply chain, using all fruit produced, since the obtained extracts had high percentages of functional ingredients. Furthermore, on a longer-term perspective, these results sensitize to the preservation of the traditional and local sweet cherry variety. Therefore, it is possible, based on the richness of BCs present in low calibre and non-compliant cherries, to obtain a diversity of new ingredients for the food industry, minimizing environmental impact, promoting the bioeconomic value of the fruit, and promoting sustainability. 
Author Contributions: Conceptualization, A.A.V.-B., A.O., and M.P.; investigation, methodology, validation A.A.V.-B., C.N., and S.R.; formal analysis, A.A.V.-B., A.O., and D.A.C.; writing-original draft preparation, A.A.V.-B.; writing-review and editing, A.O. and D.A.C.; supervision and project administration, M.P. and J.N. All authors have read and agreed to the published version of the manuscript.

Funding: This work was supported by Ministry of Agriculture and Rural Development and co-financed by the European Agricultural Fund for Rural Development (EAFRD), through the partnership agreement Portugal PDR-2020, under the project Nature Bioactive Food: Desenvolvimento de produtos e ingredientes alimentares bioativos através de recursos agrícolas endógenos portugueses para uma alimentação saudável (Ref. PDR2020-101-031531) and is a result of the Transfer Empreende project, supported by Norte Portugal Regional Operational Programme (NORTE 2020), under the PORTUGAL 2020 Partnership Agreement, through the European Regional Development Fund (ERDF).

Acknowledgments: We would like to thank the Nature Bioactive Food project (PDR2020-101-031531), Transfer Empreende project (Norte-02-0651-FEDER-000081), supported by Norte Portugal Regional Operational Programme (NORTE 2020) and the scientific collaboration of Escola Superior de Biotecnologia of Universidade Católica Portuguesa through CBQF under the FCT project UID/Multi/50016/2019.

Conflicts of Interest: The authors declare no conflict of interest.

\section{References}

1. Acero, N.; Gradillas, A.; Beltran, M.; García, A.; Mingarro, D.M. Comparison of phenolic compounds profile and antioxidant properties of different sweet cherry (Prunus avium L.) varieties. Food Chem. 2019, 279, 260-271. [CrossRef] [PubMed]

2. Berni, R.; Hoque, M.Z.; Legay, S.; Cai, G.; Siddiqui, K.S.; Hausman, J.-F.; Andre, C.M.; Guerriero, G. Tuscan varieties of sweet cherry are rich sources of ursolic and oleanolic acid: Protein modeling coupled to targeted gene expression and metabolite analyses. Molecules 2019, 24, 1590. [CrossRef] [PubMed]

3. Gonçalves, A.C.; Bento, C.; Silva, B.; Simões, M.; Silva, L.R. Nutrients, bioactive compounds and bioactivity: The health benefits of sweet cherries (Prunus avium L.). Curr. Nutr. Food Sci. 2019, 15, $208-227$.

4. Serra, A.T.; Duarte, R.O.; Bronze, M.R.; Duarte, C.M. Identification of bioactive response in traditional cherries from Portugal. Food Chem. 2011, 125, 318-325. [CrossRef]

5. Martini, S.; Conte, A.; Tagliazucchi, D. Phenolic compounds profile and antioxidant properties of six sweet cherry (Prunus avium) cultivars. Food Res. Int. 2017, 97, 15-26. [CrossRef] [PubMed]

6. Mirto, A.; Iannuzzi, F.; Carillo, P.; Ciarmiello, L.F.; Woodrow, P.; Fuggi, A. Metabolic characterization and antioxidant activity in sweet cherry (Prunus avium L.) Campania accessions: Metabolic characterization of sweet cherry accessions. Food Chem. 2018, 240, 559-566. [CrossRef]

7. Berni, R.; Cantini, C.; Romi, M.; Hausman, J.-F.; Guerriero, G.; Cai, G. Agrobiotechnology goes wild: Ancient local varieties as sources of bioactives. Int. J. Mol. Sci. 2018, 19, 2248. [CrossRef]

8. Matias, A.; Rosado-Ramos, R.; Nunes, S.; Figueira, I.; Serra, A.; Bronze, M.; Santos, C.; Duarte, C. Protective effect of a (poly) phenol-rich extract derived from sweet cherries culls against oxidative cell damage. Molecules 2016, 21, 406. [CrossRef]

9. Gómez-García, R.; Campos, D.A.; Aguilar, C.N.; Madureira, A.R.; Pintado, M. Valorization of melon fruit (Cucumis melo L.) by-products: Phytochemical and Biofunctional properties with Emphasis on Recent Trends and Advances. Trends Food Sci. Technol. 2020. [CrossRef]

10. Coelho, M.; Pereira, R.; Rodrigues, A.S.; Teixeira, J.A.; Pintado, M.E. Extraction of tomato by-products' bioactive compounds using ohmic technology. Food Bioprod. Process. 2019, 117, 329-339. [CrossRef]

11. Kerdudo, A.; Burger, P.; Merck, F.; Dingas, A.; Rolland, Y.; Michel, T.; Fernandez, X. Development of a natural ingredient-Natural preservative: A case study. C. R. Chim. 2016, 19, 1077-1089. [CrossRef]

12. Vongsak, B.; Sithisarn, P.; Mangmool, S.; Thongpraditchote, S.; Wongkrajang, Y.; Gritsanapan, W. Maximizing total phenolics, total flavonoids contents and antioxidant activity of Moringa oleifera leaf extract by the appropriate extraction method. Ind. Crop. Prod. 2013, 44, 566-571. [CrossRef]

13. Okur, İ; Baltacıoğlu, C.; Ağçam, E.; Baltacıoğlu, H.; Alpas, H. Evaluation of the Effect of Different Extraction Techniques on Sour Cherry Pomace Phenolic Content and Antioxidant Activity and Determination of Phenolic Compounds by FTIR and HPLC. Waste Biomass Valorization 2019, 10, 1-11. [CrossRef]

14. Zhang, Z.; Poojary, M.M.; Choudhary, A.; Rai, D.K.; Tiwari, B.K. Comparison of selected clean and green extraction technologies for biomolecules from apple pomace. Electrophoresis 2018, 39, 1934-1945. [CrossRef] [PubMed] 
15. Hatti-Kaul, R.; Törnvall, U.; Gustafsson, L.; Börjesson, P. Industrial biotechnology for the production of bio-based chemicals-a cradle-to-grave perspective. Trends Biotechnol. 2007, 25, 119-124. [CrossRef] [PubMed]

16. Bonifácio-Lopes, T.; Teixeira, J.A.; Pintado, M. Current extraction techniques towards bioactive compounds from brewer's spent grain-A review. Crit. Rev. Food Sci. Nutr. 2019, 1-12. [CrossRef]

17. Gonçalves, A.; Rodrigues, M.; Santos, A.; Alves, G.; Silva, L. Antioxidant Status, Antidiabetic Properties and Effects on Caco-2 Cells of Colored and Non-Colored Enriched Extracts of Sweet Cherry Fruits. Nutrients 2018, 10, 1688. [CrossRef]

18. Serra, A.T.; Matias, A.A.; Almeida, A.P.; Bronze, M.; Alves, P.M.; de Sousa, H.C.; Duarte, C.M. Processing cherries (Prunus avium) using supercritical fluid technology. Part 2. Evaluation of SCF extracts as promising natural chemotherapeutical agents. J. Supercrit. Fluids 2011, 55, 1007-1013. [CrossRef]

19. Alexandre, E.M.; Silva, S.; Santos, S.A.; Silvestre, A.J.; Duarte, M.F.; Saraiva, J.A.; Pintado, M. Antimicrobial activity of pomegranate peel extracts performed by high pressure and enzymatic assisted extraction. Food Res. Int. 2019, 115, 167-176. [CrossRef]

20. Lee, J.; Durst, R.W.; Wrolstad, R.E. Determination of total monomeric anthocyanin pigment content of fruit juices, beverages, natural colorants, and wines by the $\mathrm{pH}$ differential method: Collaborative study. J. AOAC Int. 2005, 88, 1269-1278. [CrossRef]

21. Monforte, A.R.; Martins, S.I.; Silva Ferreira, A.C. Strecker aldehyde formation in wine: New insights into the role of gallic acid, glucose, and metals in phenylacetaldehyde formation. J. Agric. Food Chem. 2017, 66, 2459-2466. [CrossRef] [PubMed]

22. Oliveira, C.M.; Barros, A.S.; Silva Ferreira, A.C.; Silva, A.M.S. Influence of the temperature and oxygen exposure in red Port wine: A kinetic approach. Food Res. Int. 2015, 75, 337-347. [CrossRef] [PubMed]

23. Gião, M.S.; González-Sanjosé, M.L.; Rivero-Pérez, M.D.; Pereira, C.I.; Pintado, M.E.; Malcata, F.X. Infusions of Portuguese medicinal plants: Dependence of final antioxidant capacity and phenol content on extraction features. J. Sci. Food Agric. 2007, 87, 2638-2647. [CrossRef] [PubMed]

24. Dávalos, A.; Gómez-Cordovés, C.; Bartolomé, B. Extending applicability of the oxygen radical absorbance capacity (ORAC- fluorescein) assay. J. Agric. Food Chem. 2004, 52, 48-54. [CrossRef] [PubMed]

25. Berni, R.; Romi, M.; Cantini, C.; Hausman, J.-F.; Guerriero, G.; Cai, G. Functional molecules in locally-adapted crops: The case study of tomatoes, onions, and sweet cherry fruits from Tuscany in Italy. Front. Plant Sci. 2019, 9, 1983. [CrossRef] [PubMed]

26. Karabegović, I.T.; Stojičević, S.S.; Veličković, D.T.; Todorović, Z.B.; Nikolić, N.Č.; Lazić, M.L. The effect of different extraction techniques on the composition and antioxidant activity of cherry laurel (Prunus laurocerasus) leaf and fruit extracts. Ind. Crop. Prod. 2014, 54, 142-148. [CrossRef]

27. Garofulić, I.E.; Dragović-Uzelac, V.; Jambrak, A.R.; Jukić, M. The effect of microwave assisted extraction on the isolation of anthocyanins and phenolic acids from sour cherry Marasca (Prunus cerasus var. Marasca). J. Food Eng. 2013, 117, 437-442.

28. Cacace, J.; Mazza, G. Mass transfer process during extraction of phenolic compounds from milled berries. J. Food Eng. 2003, 59, 379-389. [CrossRef]

29. Spigno, G.; De Faveri, D.M. Antioxidants from grape stalks and marc: Influence of extraction procedure on yield, purity and antioxidant power of the extracts. J. Food Eng. 2007, 78, 793-801. [CrossRef]

30. Alexandre, E.M.; Moreira, S.A.; Castro, L.M.; Pintado, M.; Saraiva, J.A. Emerging technologies to extract high added value compounds from fruit residues: Sub/supercritical, ultrasound-, and enzyme-assisted extractions. Food Rev. Int. 2018, 34, 581-612. [CrossRef]

31. Galanakis, C.M. Recovery of high added-value components from food wastes: Conventional, emerging technologies and commercialized applications. Trends Food Sci. Technol. 2012, 26, 68-87. [CrossRef]

32. Carrera, C.; Ruiz-Rodríguez, A.; Palma, M.; Barroso, C.G. Ultrasound assisted extraction of phenolic compounds from grapes. Anal. Chim. Acta 2012, 732, 100-104. [CrossRef] [PubMed]

33. Jerman, T.; Trebše, P.; Mozetič Vodopivec, B. Ultrasound-assisted solid liquid extraction (USLE) of olive fruit (Olea europaea) phenolic compounds. Food Chem. 2010, 123, 175-182. [CrossRef]

34. Adiamo, O.Q.; Ghafoor, K.; Al-Juhaimi, F.; Babiker, E.E.; Ahmed, I.A.M. Thermosonication process for optimal functional properties in carrot juice containing orange peel and pulp extracts. Food Chem. 2018, 245, 79-88. [CrossRef] [PubMed]

35. Vinatoru, M. An overview of the ultrasonically assisted extraction of bioactive principles from herbs. Ultrason. Sonochem. 2001, 8, 303-313. [CrossRef] 
36. Wang, L.; Weller, C.L. Recent advances in extraction of nutraceuticals from plants. Trends Food Sci. Technol. 2006, 17, 300-312. [CrossRef]

37. Kaufmann, B.; Christen, P. Recent extraction techniques for natural products: Microwave-assisted extraction and pressurised solvent extraction. Phytochem. Anal. Int. J. Plant. Chem. Biochem. Tech. 2002, 13, 105-113. [CrossRef]

38. Campos, D.A.; Gómez-García, R.; Vilas-Boas, A.A.; Madureira, A.R.; Pintado, M.M. Management of Fruit Industrial By-Products-A Case Study on Circular Economy Approach. Molecules 2020, 25, 320. [CrossRef]

39. Casazza, A.A.; Aliakbarian, B.; Mantegna, S.; Cravotto, G.; Perego, P. Extraction of phenolics from Vitis vinifera wastes using non-conventional techniques. J. Food Eng. 2010, 100, 50-55. [CrossRef]

40. Ferrentino, G.; Asaduzzaman, M.; Scampicchio, M.M. Current technologies and new insights for the recovery of high valuable compounds from fruits by-products. Crit. Rev. Food Sci. Nutr. 2018, 58, 386-404. [CrossRef]

41. Gonçalves, A.C.; Bento, C.; Jesus, F.; Alves, G.; Silva, L.R. Sweet Cherry Phenolic Compounds: Identification, Characterization, and Health Benefits. In Studies in Natural Products Chemistry; Elsevier: Amsterdam, The Netherlands, 2018; Volume 59, pp. 31-78.

42. Mateus, N.; de Freitas, V. Anthocyanins as food colorants. In Anthocyanins; Springer: Berlin, Germany, 2008; pp. 284-304.

43. Oliveira, A.; Pintado, M. Stability of polyphenols and carotenoids in strawberry and peach yoghurt throughout In Vitro gastrointestinal digestion. Food Funct. 2015, 6, 1611-1619. [CrossRef] [PubMed]

44. Ludwig, I.A.; Sanchez, L.; Caemmerer, B.; Kroh, L.W.; De Peña, M.P.; Cid, C. Extraction of coffee antioxidants: Impact of brewing time and method. Food Res. Int. 2012, 48, 57-64. [CrossRef]

45. Lopes, G.R.; Ferreira, A.S.; Pinto, M.; Passos, C.P.; Coelho, E.; Rodrigues, C.; Figueira, C.; Rocha, S.M.; Nunes, F.M.; Coimbra, M.A. Carbohydrate content, dietary fibre and melanoidins: Composition of espresso from single-dose coffee capsules. Food Res. Int. 2016, 89, 989-996. [CrossRef]

46. Díaz-de-Cerio, E.; Gómez-Caravaca, A.M.; Verardo, V.; Fernández-Gutiérrez, A.; Segura-Carretero, A. Determination of guava (Psidium guajava L.) leaf phenolic compounds using HPLC-DAD-QTOF-MS. J. Funct. Foods 2016, 22, 376-388.

47. Gonçalves, A.C.; Bento, C.; Silva, B.M.; Silva, L.R. Sweet cherries from Fundão possess antidiabetic potential and protect human erythrocytes against oxidative damage. Food Res. Int. 2017, 95, 91-100. [CrossRef] [PubMed]

48. Crupi, P.; Bleve, G.; Tufariello, M.; Corbo, F.; Clodoveo, M.L.; Tarricone, L. Comprehensive identification and quantification of chlorogenic acids in sweet cherry by tandem mass spectrometry techniques. J. Food Compos. Anal. 2018, 73, 103-111. [CrossRef]

49. Sánchez-Rabaneda, F.; Jauregui, O.; Lamuela-Raventós, R.M.; Viladomat, F.; Bastida, J.; Codina, C. Qualitative analysis of phenolic compounds in apple pomace using liquid chromatography coupled to mass spectrometry in tandem mode. Rapid Commun. Mass Spectrom. 2004, 18, 553-563. [CrossRef]

50. Gonçalves, B.; Landbo, A.-K.; Knudsen, D.; Silva, A.P.; Moutinho-Pereira, J.; Rosa, E.; Meyer, A.S. Effect of ripeness and postharvest storage on the phenolic profiles of cherries (Prunus avium L.). J. Agric. Food Chem. 2004, 52, 523-530.

51. Ju, Z.Y.; Howard, L.R. Effects of solvent and temperature on pressurized liquid extraction of anthocyanins and total phenolics from dried red grape skin. J. Agric. Food Chem. 2003, 51, 5207-5213. [CrossRef]

52. Faustino, M.; Veiga, M.; Sousa, P.; Costa, E.M.; Silva, S.; Pintado, M. Agro-food byproducts as a new source of natural food additives. Molecules 2019, 24, 1056. [CrossRef]

53. Alves-Silva, J.M.; dos Santos, S.M.D.; Pintado, M.E.; Pérez-Álvarez, J.A.; Fernández-López, J.; Viuda-Martos, M. Chemical composition and in vitro antimicrobial, antifungal and antioxidant properties of essential oils obtained from some herbs widely used in Portugal. Food Control 2013, 32, 371-378. [CrossRef]

54. Kelebek, H.; Selli, S. Evaluation of chemical constituents and antioxidant activity of sweet cherry (Prunus avium L.) cultivars. Int. J. Food Sci. Technol. 2011, 46, 2530-2537. [CrossRef]

55. Kulczyński, B.; Gramza-Michałowska, A.; Królczyk, J.B. Optimization of Extraction Conditions for the Antioxidant Potential of Different Pumpkin Varieties (Cucurbita maxima). Sustainability 2020, 12, 1305. [CrossRef]

56. Ribeiro, T.; Oliveira, A.; Campos, D.; Nunes, J.; Vicente, A.A.; Pintado, M. Simulated digestion of olive pomace water-soluble ingredient: Relationship between the compounds bioaccessibility and their potential health benefits. Food Funct. 2020, 11, 2238-2254. [CrossRef] 
57. Milea, A.Ș.; Vasile, A.M.; Cîrciumaru, A.; Dumitrașcu, L.; Barbu, V.; Râpeanu, G.; Bahrim, G.E.; Stănciuc, N. Valorizations of Sweet Cherries Skins Phytochemicals by Extraction, Microencapsulation and Development of Value-Added Food Products. Foods 2019, 8, 188. [CrossRef] [PubMed]

58. Serra, A.T.; Seabra, I.J.; Braga, M.E.; Bronze, M.; de Sousa, H.C.; Duarte, C.M. Processing cherries (Prunus avium) using supercritical fluid technology. Part 1: Recovery of extract fractions rich in bioactive compounds. J. Supercrit. Fluids 2010, 55, 184-191. [CrossRef]

59. Rajbhar, K.; Dawda, H.; Mukundan, U. Polyphenols: Methods of extraction. Sci. Revs. Chem. Commun. 2015, 5, 1-6.

(C) 2020 by the authors. Licensee MDPI, Basel, Switzerland. This article is an open access article distributed under the terms and conditions of the Creative Commons Attribution (CC BY) license (http://creativecommons.org/licenses/by/4.0/). 